\title{
Status, EMOtional DisPlays, AND THE RElationally-BASEd Evaluation OF CRIMINALS AND THEIR BEHAVIOR*
}

\author{
Lisa M. Dilks ${ }^{\mathrm{a}^{*}}$
}

\section{Tucker S. McGrimmon ${ }^{\mathrm{b}}$}

\section{Shane R. Thye ${ }^{c}$}

${ }^{a}$ Department of Sociology and Anthropology, West Virginia University, PO Box 6326, Morgantown, WV 26506. Email: lisa.dilks@,mail.wvu.edu.

${ }^{b}$ Department of Economics, University of Pretoria, Private Bag X20, Hatfield, Pretoria, South Africa 0028. Email: tucker.mcgrimmon@up.ac.za.

${ }^{\mathrm{c}}$ Department of Sociology, University of South Carolina, Sloan College Rm. 321, 911 Pickens St., Columbia, SC 29208. Email: srthye@sc.edu.

*Corresponding author. Address: Department of Sociology and Anthropology, West Virginia University, PO Box 6326, Morgantown, WV 26506. Email: 1isa.dilks@mail.wvu.edu. Phone: 304-293-0455.

Word Count: 14,415 (inclusive) 


\title{
Status, EMotional Displays, AND THE RElationally-BASEd EVALUATION OF CRIMINALS AND THEIR BEHAVIOR
}

\begin{abstract}
This research uses status characteristics theory to expand our knowledge of the effects of status variables (e.g., race, education) and emotional displays on the antecedents of sentencing evaluations of offender dangerousness and offense seriousness. We present a theoretical formulation that combines three areas of status characteristics research - reward expectations, individual evaluative settings and valued personal characteristics. The result is a quantitative measure that aggregates relative differences in demographic and emotional characteristics between offenders and their victims. The significance of this expectation advantage measure (e) in predicting evaluations of offender dangerousness and offense severity is tested using data from a vignette study. We find empirical support that expectation advantage significantly predicts these sentencing antecedents but not sentencing outcomes directly. We conclude by discussing the implications of our findings for future status and criminological research.
\end{abstract}

Keywords: status characteristics theory, valued personal characteristics, offender dangerousness, offense severity, sentencing, offender-victim dyad 


\section{Status, EMotional Displays, AND THE RElationally-BASEd EVALUATION OF CRIMINALS AND THEIR BEHAVIOR}

\section{Introduction}

Legal guidelines require that sentences be determined by assessments of an offender's habitualness of criminal behavior - offender dangerousness - and the severity of the crime committed - offense severity (Blumstein et al. 1983). The more dangerous an offender is believed to be and the more severe the crime they committed, the longer the mandated sentence (Spohn 2009). According to statutory law, offender dangerousness should be determined by an offender's prior criminal record while prescribed legal factors for evaluating offense severity include weapon use, excessive harm to the victim, and crime type (Blumstein et al. 1983). But research has found that other factors, particularly demographic characteristics and emotional displays, also influence evaluations of offender dangerousness and offense severity.

For example, Steffensmeier and Demuth (2006, p. 246) argue that evaluations of offender dangerousness and offense severity may be impacted by an offender's position in the social structure, as determined by gender, race or ethnic status. Empirical research has confirmed that these social characteristics do indeed affect evaluations of offender dangerousness and offense severity (Albonetti 1991, 1997; Bridges and Crutchfield 1988; Bridges and Steen 1998; Fearn 2005; Kautt 2009b; Kramer and Steffensmeier 1993; Moore and Miethe 1986; Steffensmeier and Demuth 2000; Steffensmeier, Ulmer and Kramer 1998; Zatz 1984). But social structure, particularly in small groups, is not determined solely by an individual's own characteristics but rather those characteristics relative to the characteristics of others (Berger and Webster 2006).

Accounting for this relational consideration, offender-victim dyad research has investigated differences in the social composition of these dyads and found that varying the relative differences between offender and victim does impact sentencing (Baldus, Woodworth, and 
Pulaski 1990; Curry, Lee and Rodriguez 2004; Franklin and Fearn 2008; Holcomb, Williams and Demuth 2004). Although the majority of this research does not focus on evaluations of offender dangerousness and offense severity it is telling that relative differences do matter in sentencing decisions.

Additional research has shown that emotions like remorse tend to reduce sentencing recommendations while displaying a lack of regret increases them (Dane and Wrightsman 1982; Drass and Spencer 1987; Robinson, Smith-Lovin and Tsoudis 1994; Rumsey 1976; Spencer 1983; Tsoudis and Smith-Lovin 1998). It is presumed that these emotional displays would affect the antecedents of the sentencing process, offender dangerousness and offense severity, similarly. But to account for emotions as well as relative differences in social characteristics requires an aggregative and relational mechanism. We argue that a social psychological theory of group dynamics, status characteristics theory, is well suited to aggregate both social characteristics and emotions and provide testable predictions regarding the composition of an offender-victim dyad and its impact on evaluations of criminals and their behavior.

Specifically, we rely on contemporary extensions of status characteristics theory to reward and evaluative settings to develop an argument that describes how cultural beliefs about demographic characteristics and emotional displays affect evaluations of offender dangerousness and offense severity. These characteristics are combined into an expectation advantage using the mathematical structure developed in Berger et al. (1977). This expectation mimics the relational processes suggested by the offender-victim dyad research by aggregating salient status characteristics into a single numeric value that represents an individual's expectation advantage over another. This measure becomes our primary explanatory variable of evaluations of criminals and their behavior. We test the relevance of our measure of expectation advantage for 
the evaluations of offender dangerousness and offense severity using data from a factorial vignette study. This vignette presents subjects with a description of a drunk driving accident wherein the status of the offenders and victims (high, low) are varied. The emotional displays of the offender and victim (neutral, sad/remorseful) are also varied using behavioral cues embedded in transcribed testimonies. Our status-based arguments suggest that as the status advantage of offenders over victims increase, evaluations of offender dangerousness and offense severity decrease. We conclude by discussing our findings in the larger context of applying sociological accounts of status and emotion to the sentencing literature and show how these literatures are jointly instructive in improving our understanding of the mechanisms that affect the criminal adjudication process.

\section{The Evaluation of Criminals and Their Behaviors}

\subsection{Offender Dangerousness, Offense Severity and Sentencing}

Steffensmeier et al. (1998) argue that judges consider three focal concerns when making sentencing decisions: blameworthiness, community protection, and practical constraints (see also Spohn and Holleran 2000; Steffensmeier 1980; Steffensmeier and Demuth 2001; Steffensmeier et al. 1993; Ulmer 1997; Ulmer and Johnson 2004). ${ }^{1}$ Blameworthiness refers to the severity of the criminal offense. Community protection focuses on the need to incapacitate offenders due to perceived levels of dangerousness and the likelihood of recidivism. Practical constraints focus on organizational issues affecting the criminal justice system such as prison space. According to Kautt (2009a) and Blumstein et al. (1983), the majority of sentencing guidelines involve two of these focal concerns: offense severity (i.e. blameworthiness) and offender dangerousness (i.e. community protection). Although guidelines vary across jurisdictions, many state that offender

\footnotetext{
${ }^{1}$ While juries do not impose sentences, jurors are allowed to recommend sentences to judges after finding someone guilty. Judges rarely over turn these recommendations (Demleitner et al. 2004). This suggests that the evaluations by legal professionals are often consistent with laymen evaluations.
} 
dangerousness should be determined mainly by an offender's prior criminal record (Spohn 2009). Some guidelines however allow for offender acceptance of responsibility or level of remorse to play a role (Demleitner et al. 2004). Factors for evaluating offense seriousness generally include crime type, weapon use and excessive harm to the victim (Demleitner et al. 2004; Spohn 2009). Offenders who commit more serious crimes and have more serious criminal histories receive the longest sentences (Spohn 2009, p. 86).

But despite these guidelines, a number of studies find that to reach conclusions about offender dangerousness and offense severity, legal actors "may be influenced by an offender's position in the social structure" as determined by gender, race or ethnic status (Steffensmeier and Demuth 2006, p. 246; see also Albonetti 1997; Holleran and Spohn 2004; Kautt and Spohn 2002). Albonetti (1991, p. 247) argues that judges develop "patterned responses" using stereotypes that link offender characteristics such as race, age or gender to evaluations of offender dangerousness and offense severity. Much empirical research has verified these claims. ${ }^{2}$

Of these characteristics race is the most heavily studied. Racial stereotypes linking race and ethnicity to criminality find that minority defendants are perceived as more dangerous, threatening and culpable than white defendants (Albonetti 1991, 1997; Bridges and Crutchfield 1988; Bridges and Steen 1998; Farrell and Swigert 1978; Freiburger et al. 2010; Kramer and Steffensmeier 1993; Miethe and Moore 1986; Steffensmeier and Demuth 2000; Steffensmeier et al. 1998; Zatz 1984, 1985). Similarly, those individuals evaluated as committing the most serious crimes are more likely to be non-white (Moore and Miethe 1986; Spohn, Gruhl and Welch 1981-

\footnotetext{
${ }^{2}$ For research on gendered evaluations of offense severity and offender dangerousness see Albonetti (1991, 2002), Forsterlee et al. (2004), Steffensmeier (1980) and Steen, Engen and Gainey (2005). Ethnic variations were the focus of study in Albonetti (1991, 2002), Farrell and Swigert (1978), Kramer and Ulmer (2002), Miethe and Moore (1986), Spohn and Holleran (2000), Steffensmeier and Demuth (2001), Ulmer (1997), Unnever (1982) and Zatz (1984). Nobling, Spohn and DeLone (1998) and Spohn and Holleran (2000) also examined the role of employment status on these evaluations.
} 
82). Research by Kautt (2009a, b) also found that defendant race significantly predicted overall evaluations of offense severity, net of sentencing guidelines.

In contrast to demographic characteristics, the role of emotions in evaluations of offender dangerousness and offense severity has received much less attention. When offenders show obvious remorse, their behaviors are seen as less deviant and they are perceived to be less likely to engage in future criminal activity, thereby reducing the severity of their sentence (Drass and Spencer 1987; Robinson, Smith-Lovin, and Tsoudis 1994; Rumsey 1976; Spencer 1983; Tsoudis and Smith-Lovin 1998). In contrast, a lack of regret can signal that criminal behavior is typical of an offender, suggesting a higher likelihood of recidivism and continued deviance. This type of evaluation leads to an increase in the length of sentences recommended for non-emotional perpetrators (Dane and Wrightsman 1982; Robinson et al. 1994; Tsoudis and Smith-Lovin 1998).

Evaluations of offender dangerousness and offense severity are also influenced by interactions between social characteristics as well as social and emotional characteristics. For example, analyses of interview data from a sample of judges found that the criminal records of young black males were evaluated as more serious and indicative of future criminal behavior as compared to other types of defendants (Steffensemeier et al. 1998). As a result, young black males were sentenced more severely than any other race-gender-age combination. Niedermeier, Horowitz, and Kerr $(1999,2001)$ focus on the connections between remorse and occupational status on evaluations of guilt in cases of medical malpractice. A series of experiments found that jurors perceived high-status doctors (medical directors) as guiltier than low-status doctors (second-year interns) when remorse was shown, but the opposite pattern was evident when no remorse was shown. The implication is that status and emotion interact. 
We argue the role of these emotions is important for criminal evaluations because they are often used as predictors of moral behavior (Eisenberg 2000). For example, negative emotions tend to be linked with expectations of immorality (Mikula, Scherer and Athenstaedt 1998; Scher 1997). These expectations of morality affect evaluations of offender dangerousness, offense severity, and sentencing decisions because criminal theory describes punishment as premised on the desire to punish people with low moral character (Fletcher 2000). Furthermore, these expectations of morality vary based on attachment to social groups or "criminal castes" (Yankah 2003-2004, p. 1026). For example, blacks and unremorseful offenders are characterized as amoral and consequently punished harsher than their white and/or remorseful counterparts (Bridges and Steen 1998). We use these insights to theoretically link status, emotion and evaluations of criminal behavior.

\subsection{The Offender-Victim Dyad}

Offender characteristics, emotions, and their interactions are one source of influence on evaluations of offender dangerousness and offense severity. Black (1976) argued for a more relational view of law where the combination of victim and offender characteristics impacts legal outcomes. Recent empirical tests of this assertion find that the composition of offender-victim dyads in terms of race and gender impact criminal case processing and sentencing decisions (e.g., Johnson, Van Wingerden and Nieuwbeerta 2010; Martin 2013; Roberts and Lyons 2009). For example, Baldus et al. (1990) and Holcomb et al. (2004) found that African American offenders who murdered whites were more likely to receive the death penalty than white murderers of African Americans or other non-white victims. ${ }^{3}$ Other research on the effects of the gender composition of offender-victim dyads has found that male offenders who target female

\footnotetext{
${ }^{3}$ Additional effects on legal outcomes due to the racial differences between offenders and victims can be found in the following: Baumer, Messner and Felson (2000), Hunter, Ralph and Marquart (1993); Kingsnorth et al. (1998, 1999, 2001), LaFree (1980), Myers and LaFree (1982) and Walsh (1987).
} 
victims receive the harshest sanctions as compared to other gender dyads (Curry et al. 2004; Franklin and Fearn 2008). Although the impacts of offender-victim dyads on sentencing decisions has been established, to our knowledge dyadic considerations have not been examined in reference to the antecedents of sentencing, offender dangerousness and offense severity.

The impact of offender and victim characteristics such as race, gender, and emotional displays is complex, interactive, and relational. We argue the key to fully understanding evaluations of offender dangerousness and offense severity is not simply the aggregation of offender characteristics but accounting for the relative differences in these characteristics between offenders and victims. We argue that status characteristics theory can incorporate the aggregation of status and emotional display differences between offenders and victims to generate a measure of an offender's expectation advantage that affords us a theoretical prediction regarding the impact of these differences on evaluations of offender dangerousness and offense severity.

\section{Status Characteristics Theory}

Status characteristics theory (hereafter SCT), part of the larger expectation states program, emerged as an effort to understand the materialization of power and prestige gradients in taskbased and collectively-oriented groups (Berger et al. 1977). Specifically, SCT focuses on the impact of social attributes (like race and gender) and behaviors that generate differences in expectations of competence within these types of groups (Berger, Cohen, and Zelditch 1972; Berger, Conner, and Fisek 1974; Humphreys and Berger 1981). The theory asserts that actors form "performance expectations" for themselves and others in groups. These then hierarchically rank group members into a power and prestige order. Those who occupy higher positions in the expectation hierarchy are predicted to have higher positions in terms of power and prestige. 
Group members considered lower in the expectation hierarchy are predicted to occupy lower positions (see Webster and Foschi [1988] for a full review of how these social hierarchies emerge). The resulting order creates a structure of intragroup inequalities wherein lower status members have less opportunity to participate, participate less, are less influential and are evaluated more poorly than higher status counterparts (Berger et al. 1972, 1974). Thus, observable status characteristics translate into expectations of competence and subsequent behavioral inequalities.

Any social attribute or behavior can be a status characteristic if it differentiates individuals into at least two categories wherein individuals possessing the more valued state of the characteristic are widely believed to be more socially valued and competent (high status) than those occupying the complementary categories (low status). SCT specifically identifies two types of characteristics - diffuse and specific - that create expectations of competency. A diffuse status characteristic (D) exists in a particular culture if and only if $(i)$ one state is more highly valued than the other state, (ii) to each state of D there corresponds a distinct set of specific, characteristics, and (iii) to each state of D there is also a corresponding set of general expectations (Berger et al. 1977, p. 244). For example, a characteristic such as occupation would be a diffuse status characteristic if $(i)$ being a doctor is more highly valued than some other occupation, such as nurse, $(i i)$ doctors are expected to be more competent at specific tasks such as surgeries, and (iii) doctors are generally expected to be more capable at a wide range of tasks. In contrast, a specific status characteristic (C) satisfies conditions (i) and (ii), but not (iii). For example, mathematical or reading ability may function as specific status characteristics. Empirical research finds that educational attainment, race, gender, age, beauty, and occupation 
operate as status characteristics. ${ }^{4}$ At least within the United States, males, whites, the middle aged, those who are highly educated, and those who are physically attractive are associated with greater generalized expectations and therefore high status (Berger and Webster 2006). Diffuse and specific status characteristics are combined to produce a numerical measure of status differences - termed an expectation advantage $(e)$ - using the mathematical structure developed in Berger et al. (1977). This measure can range from -2 to 2 where higher values indicate more numerous positive status characteristics for one individual relative to another. ${ }^{5}$

The scope of SCT was originally limited to collectively orientated task situations where 1) individuals are primarily motivated to complete a task that has associated with it clear perceptions for task success and task failure (i.e. task orientation) and 2) it is both necessary and legitimate for group members to consider their own and other's performance in order to complete the task (i.e. collective orientation) (Correll and Ridgeway 2003). However, new research finds that status organizing processes also occur in more individualized situations. Specifically, SCT has been extended to individual evaluative settings where individuals are compelled to consider the anticipated future performance of themselves (Correll 2004; Erickson 1998; Lovaglia et al. 1998; Steele 1997) or others (Foschi 1989; Foschi, Lai, and Siegerson 1994) in order to arrive at accurate assessments of their own or other's performance (Foschi 2000). According to Erickson (1998), the extension to individual evaluative settings is based on SCT's requirement that individuals consider performance expectations relative to one another, a requirement that is produced in a collective task setting but also in a variety of others. Thus, any situation that

\footnotetext{
${ }^{4}$ A plethora of empirical studies have supported the assertions of SCT and have found that educational attainment (Markovsky, Berger and Smith 1984; Zelditch, Lauderdale and Stublarec1980), race (Cohen and Roper 1972; Webster and Driskell 1978), gender (Lockheed and Hall 1976; Meeker and Weitzel-O'Neill 1977), age (Freese 1974; Kelley et al. 2009), beauty (Webster and Driskell 1983), and occupation (Webster et al. 1998) operate as diffuse characteristics.

${ }^{5}$ See the appendix in Berger et al. (1992) for details regarding these calculations. Also, Balkwell (2000) provides an online tool for calculating expectation advantage and Melamed (2011) provides a downloadable Excel file for more advanced calculations.
} 
creates pressures for individuals to assess expectations in a relative manner allows status generalization processes to occur (Correll and Ridgeway 2003). These types of situations include the evaluation of job candidates who differ in terms of status but not qualifications (Foschi et al. 1994), the standards individuals' employ to evaluate their own task ability in non-group settings (Correll 2001), tasks involving the presence of stereotype threat (Steele 1997), and settings where individuals take mental ability tests (Lovaglia et al. 1998).

\subsection{Reward Expectations Theory}

In situations involving the evaluation and eventual sentencing of criminals, the relationship between diffuse status characteristics and expectations for task competency does not seem particularly relevant. Instead, what is more applicable is a determination of a criminal's morality or blameworthiness. In other words, judges and jurors may ask themselves "What outcome does a criminal like this deserve?" Furthermore, the assignment of a power and prestige ordering that gives high status individuals more opportunities to perform in a group or have their contributions to the group task evaluated positively is not a likely outcome when evaluating criminals and their crimes. Although theory and research in SCT have primarily focused on expectations related to task competence and the resulting power and prestige ordering, status researchers have also begun to explore status processes in non-task situations where competency may not be the most applicable expectation state. For instance, the original conception of a generalized expectation state also included expectations of morality (Berger et al. 1972). In this sense, status characteristics should also imply how generally good or bad an individual is relative to another. However, while the idea of moral expectations has not been directly explored by status researchers an indirect set of moral expectations have been explored by Berger et al.'s (1998) extension, reward expectations theory. This extension also replaces the emphasis on power and 
prestige orderings with an examination of how groups and individuals allocate rewards or goal objects.

In contrast to expectations of competency, reward expectations are "implicit, shared, normative anticipations about who 'will and ought to' get what in a group" (Hysom and Fisek 2011, p. 1269). According to Berger et al. (1998), reward expectations take on a "moral quality" absent with task expectations. Specifically, the allocation of certain rewards is not just expected, but judged to be right or proper. Any distribution of rewards that violate these expectations is considered wrong or improper (Berger et al. 1998, p. 121). Reward expectations stem from information about general reward practices in the larger social system. Hence, individuals are likely to form reward expectations that resemble common societal practices. Berger et al. (1998, p. 127) formally define the sources of reward information as referential structures and outline three types: ability, outcome, and categorical. Ability referential structures are most closely related to the concept of task competency in the original SCT formulation and imply that people who are more competent should receive more rewards than people who are less competent. Similarly, outcome referential structures are beliefs that those who succeed at tasks usually receive more rewards than people who fail at them. Finally, categorical referential structures represent the belief that individuals who possess the positive state of a diffuse characteristic should receive more rewards than those possessing the negative state.

Reward expectations theory asserts that individuals 1) form expectations for rewards for actors in salient status situations which then 2) determine the subsequent allocation of either literal (e.g., money) or symbolic rewards (e.g., powerful social positions, medals), also called goal objects. This generalization process mimics the process that produces group power and prestige orderings based on task competency (see Berger et al. [1998] for a thorough 
explanation). For example, a categorical referential structure could become salient if a diffuse status characteristic differentiates two actors. Following from the relationship between task competency and diffuse status, categorical referential structures imply that those who occupy the high status states of common diffuse characteristics (race, sex, age, education and occupational prestige) will be seen as deserving of more socially valued rewards as compared to low status individuals. A series of studies in the reward expectations literature finds such an effect, not only for categorical referential structures (Melamed 2011), but also for ability (Fisek and Hysom 2008; Hysom and Fisek 2011; Wagner 1995) and outcome structures (Hysom 2009). In terms of our study, this suggests that higher status offenders should receive more lenient sentences.

\subsection{Appropriate Emotional Displays as Status}

As previously discussed (section 2.1), emotional displays by offenders and victims can impact evaluations of offender dangerousness, offense seriousness, and sentencing outcomes. In social science research the terms emotion and sentiment are often used interchangeably. We assume, following Thoits (1990) and (Hochschild 1979, 1983), that emotions are controllable behaviors that are governed by situational cues or norms that may be displayed through physiological changes or expressions that can be labeled (i.e., remorse, sadness). Further, we agree with Ridgeway (1994) that sentiments are stable appraisals of individuals, such as liking or disliking, that represent the emotional content of a relationship. ${ }^{6}$ Both emotions and sentiments can be incorporated under the SCT framework.

Early status research illustrated that sentiments, in the form of liking or disliking a high status actor, affected that actor's influence (Bales 1953). Since then, status characteristic theorists have speculated that sentiment may be incorporated into expectation states theory, either directly operating as a specific or diffuse characteristic or indirectly altering the effects of status on

\footnotetext{
${ }^{6}$ See Stets (2003) for a more detailed elaboration of the relationships between emotions and sentiments.
} 
behavior (Fisek and Berger 1998). Driskell and Webster (1997) provided evidence that sentiments by one actor regarding another do not affect that actor's performance expectations. Extending this finding, Bianchi (2005) and Bianchi and Lancianese (2007) provided experimental evidence that negative and positive sentiments served as "moderators" of status processes in task-oriented groups. Similar to Driskell and Webster (1997), Bianchi (2005) found that being liked or disliked did not affect performance expectations and the status hierarchy but similar to Bales (1953) her results showed that such sentiments did affect behavior through differences in an actor's level of group influence. In studies of emotions and status, Lovaglia and Houser (1996) and Houser and Lovaglia (2002) concluded that emotions (happiness, sadness, etc.) influence the status process directly and should be combined with other status elements to modify the resulting hierarchy.

Shelly's (2001) vignette study is perhaps the most relevant to our own since it involved an evaluative setting in which subjects made evaluations of two hypothetical others. Shelly found that sentiment, again operationalized as liking or disliking the other, affected evaluations (his study 2). Our focus is slightly different. We instead examine how the actual emotion displayed by individuals affects their overall levels of status. Furthermore, based on the offender-victim dyadic research described in section 2.2 , we also assume that the relative difference between offender and victim emotional displays will affect an individual's expectation advantage and subsequent evaluations of offender dangerousness and offense severity. ${ }^{7}$ SCT theorists have already created the theoretical apparatus to accommodate sentiments. Our extension asks how relative differences in emotional displays should be modeled using this existing framework.

\footnotetext{
${ }^{7}$ This is not to suggest that sentiment does not play a role in evaluations of offender dangerousness and offense severity. For example, research finds that similarities between oneself and another leads to liking (a sentiment) (Byrne 1971; Lee and Bond 1996; Mackinnon, Jordan and Wilson 2001; Newcomb 1961). Several studies illustrate that jurors are more sympathetic to defendants who share similar attitudes, race, gender or religion (Selby, Calhoun and Brock 1977; Towson and Zanna 1983; Ugwuegbu 1979).
} 
We propose that the theoretical link between emotional display and the existing SCT framework is Driskell's (1982) concept of valued personal characteristics. Like diffuse and specific status characteristics, valued personal characteristics (hereafter VC) have differentially evaluated states, where possessing the highly valued state is associated with high levels of honor, esteem or desirability. However, while the preferred state of a status characteristic is constant and culturally stable, the preferred state of a VC depends on the social norms that govern a situation (Driskell 1982; Webster and Hysom 1998). A further distinction is that VCs are assumed to be controllable by individuals, for example, displaying empathy, sensitivity, trustworthiness, and friendliness when appropriate (Driskell 1982). In contrast, status characteristics are largely ascribed qualities that cannot be easily altered. Individuals adhering to situational norms can be said to occupy the preferred state of a $\mathrm{VC}$ while those who deviate from them occupy the less desirable state. This implies that those occupying the preferred state of a $\mathrm{VC}$ are associated with higher levels of morality, esteem, or desirability and are seen as more competent (or deserve more rewards) than those occupying the less desirable state (Driskell 1982).

The impact of VCs on one's expectation advantage depends on the presence or absence of other status characteristics. Driskell (1982, p. 233) argued that when individuals are equated on all status characteristics except for a VC, it will operate analogous to a diffuse status characteristic, directly influencing general performance expectations and subsequent task outcomes. In contrast, because VCs carry no inherent performance connotations, they will not be linked to expectations when other differentiating status information is present. However, this is not to say that VCs will have no influence on status processes. Driskell $(1982$, p. 232) asserts, but does not formally test, that VCs may operate through a non-performance element and convey 
"other" connotations or information relevant to the situation. Driskell (1982) theorizes that this induced "positivity" element will become linked to task outcomes rather than general expectations.

\subsection{A Status Approach to Evaluating Criminals and Their Behavior}

Although we formally list our hypotheses in section 4.4, here we briefly review our theoretical argument. ${ }^{8}$ The social characteristics and emotional displays of the offender and the victim matter for assessing the moral character of offenders, which has been shown to affect sentencing outcomes. By extension, we assert that status and emotion should similarly impact important sentencing antecedents, namely perceptions of offender dangerousness and offense severity.

First, we assume the social demographics of offenders and victims operate as diffuse status characteristics. We specifically focus on race and education, both of which have previously been shown to activate status generalization processes (Cohen and Roper 1972; Markovsky, Berger and Smith 1984; Webster and Driskell 1978; Zelditch, Lauderdale and Stublarec 1980). Using Berger et al.'s (1998) reward expectations theory extension, we argue that differentiation on these characteristics between offenders and victims activates categorical referential structures, associating different reward levels with high and low status. Based on findings by Melamed (2011), we assume that these referential structures will dictate that high status actors deserve

\footnotetext{
${ }^{8}$ Our research is not the first to apply SCT to criminal sentencing. Unnever and Hembroff (1988) used Hembroff's (1982) version of status characteristics and expectation states to examine racial and ethnic sentencing disparities among male drug offenders. Hembroff's version of SCT differs from Berger et al.'s (1977) original theory, by using performance characteristics sets, a "collection of interrelated specific abilities, behaviors, dispositions or task characteristics" such as "math ability, visual acuity, temperament, or self-discipline" in lieu of specific characteristics (Unnever and Hembroff 1988, p. 58). They found empirical support for their argument that consistent case-related characteristics of defendants (e.g., number prior convictions, employment status, etc. all point to incarceration or probation) eliminate the influence of race and ethnic status on sentencing decisions. However, when case-attributes are inconsistent, sentencing disparities in punishment occur that favor high status (whites) over low status offenders (blacks and Hispanics).
} 
relatively more rewards than low status actors. Such structures should then guide judges and jurors in their evaluations of offender dangerousness and offense seriousness (i.e., goal objects). In the evaluation of criminals, a "reward" will manifest as lower criminal evaluations. Therefore, we argue that it will be seen as moral, proper and right to assign lower evaluations of offense seriousness and offender dangerousness to high status white and highly educated offenders. Punishing these individuals with harsh evaluations would run counter to generalized categorical referential structures, making such distributions of evaluations seemingly wrong or improper.

Additionally, we argue that the emotional displays by offenders and victims operate as valued personal characteristics in evaluations of offender dangerousness and offense severity. The displays of emotion by victims and offenders $(i)$ depend on emotional norms governing these situations and (ii) are controllable by individuals. Criminal evaluative settings dictate that the appropriate display of emotion for perpetrators should be remorse for committing a moral wrong such as a crime (Heise and Thomas 1989; Lazowski 1987) while appropriate displays of emotion for victims should convey distress and sadness given the atrocities perpetrated against them (Tsoudis and Smith-Lovin 1998). In hypothesizing emotional display as a VC, it is important to point out that we are not asserting that emotions in general are VCs. Instead, it is only the display of situationally-appropriate emotions that constitute a VC. For example, it may be generally preferred that people display happiness (positive state of VC) rather than sadness or no emotions (negative state). However, in a criminal setting, a happy offender would probably not be given high status based on their emotion. A happy offender may suggest an individual who takes pride in criminal activity, thereby indicating to judges and jurors someone who is inherently dangerous and likely to recidivate. Therefore, we argue that only a specific and appropriate type of emotional display represents a $\mathrm{VC}$ in our setting. By displaying the 
appropriate emotions of remorse and sadness, the offender and victim, respectfully, imply that they accept the rules and norms governing the situation and their behavior is morally affirming (positive state of VC). When the individual behaves emotionally as if no harm has been committed (relaxed, unconcerned), they are not indicating their acceptance of the rules and norms governing the event and their behavior is not affirming (negative state of VC).

Therefore, the relative difference in diffuse and valued personal characteristics between offender and victim can be aggregated using the mathematical structure developed by Berger et al. (1977) to create the offender's expectation advantage relative to the victim. This gives us a theoretical prediction regarding how differences in social characteristics and appropriate emotional displays affect evaluations of offender dangerousness and offense severity. The larger an offender's expectation advantage, the higher the status of the offender relative to the victim. Consequently, as an offender's expectation advantage increases, evaluations of dangerousness and crime severity will decrease.

\section{Data and Methods}

To examine the joint effect of status and emotion on the evaluations of an offender's dangerousness and the severity of their crime, we develop a vignette study wherein offenders have committed the same crime but the race, education and emotional displays of both the offender and victim are varied. The use of vignettes in survey questionnaires that manipulate offender and victim characteristics has been a longstanding feature of research on jury and judge decision-making (e.g., Ferrell et al. 1977; Robinson et al. 1994; Rose and Prell 1955; Steffensmeier 1977; Stephan 1975; Tsoudis and Smith-Lovin 1998). However, these surveys and experiments generally involve the use of college student subjects, posing a problem for the usefulness and generalizability of these studies. To evaluate the validity of these concerns, 
Steffensmeier and Kramer (1982) conducted a vignette experiment with three different populations: students, general citizenry, and prison inmates. They found considerable overlap in the sentencing decisions of the three groups, suggesting the viability of using student samples for this type of research.

\subsection{Participants}

Vignettes were randomized and administered to 541 undergraduate students (200 males and 341 females) in 10 classes from various departments at a large southeastern university. Upon entering the classroom, students were told that we were interested in studying their evaluations of various crimes, offenders, victims and the sentence they would assign based on case information and testimonies from courtroom proceedings. Students read one vignette each and responded to a list of survey questions related to our variables of interest in typically 10 to 15 minutes.

\subsection{Stimuli}

The criminal case presented to all subjects involved an incident of drunk driving and was adapted from vignettes used by Robinson et al. (1994) and Tsoudis and Smith-Lovin (1998). The vignette describes an offender who ran a red light while intoxicated and hit the victim's car. The victim sustained injuries that left him confined to a wheelchair. To manipulate status, the race and education level of the offender and victim were varied. Offenders and victims are either high status (white and college educated) or low status (African-American and high school educated). Sex and age are held constant; all victims and offenders are 23-year-old males. Emotional displays are manipulated by embedding non-verbal emotional behaviors in the testimonies of the victim and offender. An emotionless victim or offender is described as relaxed and unconcerned. They "lean back in their chair" and "stare straight ahead" while testifying. On the other hand, a 
sad victim or remorseful offender is described as unhappy and crying. They "hold their hands on their lap and intertwine their fingers," "look down at the floor" and "weep." Combining these manipulations yields a 2 (offender status) x 2 (offender emotional display) x 2 (victim status) x 2 (victim emotional display) design. Appendix A includes an example of the vignette condition for a high status, emotionless offender and a low status, distressed/sad victim.

We argue that our vignette and the evaluation of the offender and his behavior meet the criteria for an individual evaluative setting under recent SCT scope extensions. There are two main reasons these criteria are satisfied. First, we provide subjects with information on both the offender and the victim. Recall that status processes in individual evaluative settings should arise when individuals are forced to evaluate relative performance and/or reward expectations. In our study, the presence of status characteristics for both an offender and their victim provides the information necessary for these relative assessments. Second, the task of evaluating an offender's dangerousness and the severity of their crime is fraught with social pressures to make accurate assessments. For example, judges and jurors should not want to release dangerous criminals back into society too early. Therefore, it is assumed that participants, like judges and jurors, will consider the future behavior of the offender by calculating the likelihood of recidivism before assigning evaluations and recommending a sentence. Furthermore, participants should also want to assign punishments that "fit the crime." It would be unjustified to sentence an offender to a life sentence for jaywalking or give a confessed murderer probation. Therefore, we expect status generalization to occur as participants evaluate an offender's dangerousness, the severity of their crime and ultimately assign final punishment.

\subsection{Independent Variable}

Our primary independent variable is the expectation advantage of the offender relative to the 
victim. This value is generated using graph-theoretic procedures that combine the states of an offender and victim's diffuse status characteristics, in our study race and education, as well as appropriate emotional displays as VCs into an expectation advantage (e) (Berger et al. 1977). The graphs are drawn and $e$ is calculated from the perspective of the study participant $(\mathrm{P})$ who is evaluating an offender $\left(\mathrm{O}_{1}\right)$ relative to their victim $\left(\mathrm{O}_{2}\right) .{ }^{9}$ Notice that the graphs do not include the status information of the study participant. However, we will control for these characteristics in our analysis (see Section 4.5 below for an elaboration on this point).

Consistent with the extension of SCT to reward expectations (Berger et al. 1998), we model salient diffuse status characteristics and VCs as influencing reward expectations (R) and goal objects $(\mathrm{G})$ rather than creating expectations of competency and task performance since evaluations of offense seriousness and offender dangerousness do not constitute a "task" in the traditional SCT context. When the offender and victim are differentiated on diffuse status characteristics (D, i.e., race and education), appropriate emotional display (VC) will not affect reward expectations. Instead, we follow Driskell's (1982) recommendation that a VC will convey some "other" information (i.e., positivity/negativity) that will then be linked to outcomes, in this case goal objects (G). Driskell never formally defines this "other information" but offers the following example: "Possessing a VC such as empathy may imply the possession of other nonperformance elements such as teamwork, group loyalty, cooperation, etc.” (1982:232). Based on Driskell's example, we provide an initial definition of positivity/negativity $(\Pi+/ \Pi-)$ as an induced status element that provides nonperformance information regarding an actor's qualities

\footnotetext{
${ }^{9}$ This "self-and-two-other situation" was previously examined in Foschi et al. (1994) in the case of third party evaluations of two job candidates. In that paper, the authors state that the SCT-based and graph theoretic double standards theory in Foschi (1989) does extend to these contexts. However, the authors do not provide a formal graph theoretic representation. To our knowledge, Shelly (2001: Figure 1) provides the first formal self-and-two-other graphical representation capturing sentiment relationships between two persons, $\mathrm{X}$ and $\mathrm{Y}$, who are observed by a third actor, $\mathrm{p}$.
} 
or capacities. ${ }^{10}$ To our knowledge, this type of relationship regarding VCs and outcomes in the presence of other status information has not been formally tested. ${ }^{11}$

When coupled with information on diffuse characteristics in the context of criminal evaluations, displays of appropriate emotion may provide additional information regarding the qualities or capacities of the victim and offender. For example, the emotional state of the offender may offer insights about their likelihood of recidivism. An offender who displays remorse may be perceived as someone who does not typically violate norms or laws. Their distress over their crime $(\mathrm{VC}+)$ may communicate that his or her behavior is not typical $(\Pi+)$ thus making recidivism less likely and lowering evaluations of offense seriousness and offender dangerousness $\left(\mathrm{G}^{+}\right)$. In contrast, an unemotional offender (VC-) may signal to an observer that he or she typically violates social norms and laws (П-). The habitualness of this behavior may lead one to infer that he or she will likely recidivate thereby increasing criminal evaluations (G-). A parallel argument can be made for victims. Research on victim emotion has found that emotional reactions to crime signal the blameworthiness or responsibility of the victim for their own victimization (Karasawa 1995). When victims are distraught or sad (VC+) it suggests that they are "nice" people $(\Pi+)$ who did not deserve poor treatment (Tsoudis and Smith-Lovin 1998). In response, these victims are seen as less blameworthy and culpability for the crime is placed squarely on the offender, increasing evaluations of dangerousness and crime seriousness (G+) (Tsoudis and Smith-Lovin 1998). In contrast, neutral or unconcerned victims (VC-) give the impression that they are unaffected by such negative acts and may actually share in the blame

\footnotetext{
${ }^{10}$ This proposed definition of positivity/negativity borrows from Shelly's (2001) principle of sentiments and idealization. In this principle, Shelly (2001:76) asserts that individuals will draw inferences of another's qualities and abilities that compliment their liking or disliking of that other. For example, if an individual likes another actor, $(\mathrm{L}+)$, they will associate other positive qualities and capabilities with that actor $(\mathrm{I}+)$. The opposite is true for actors an individual may dislike. Shelly's (2001) principle builds on the consistency principle developed by Heider (1958). ${ }^{11}$ Driskell (1982:236) concluded that "the strength of generalization from a personal characteristic, however, is in question and further research is needed to specify the process more clearly." We return to this point in our discussion.
} 
for the incident (П-). As such, observers may conclude that the offender and victim share responsibility, leading to lower evaluations (G-) (Karasawa 1995).

When offenders and victims are not differentiated on diffuse characteristics, we assume that appropriate emotional display will enter the calculation of $e$ like a diffuse status characteristic, directly influencing reward expectations (R). According to Driskell (1982:233), even though VCs have no inherent performance connotations, when a VC is the only basis for differentiation between two actors, the knowledge of the differential evaluation of the characteristic (i.e., one state is preferred over another) should be sufficient to allow it to function as a diffuse characteristic and therefore serve as a basis for performance expectations. In other words, when one actor possesses the high state of a $\mathrm{VC}(+)$ and another actor the low state (-), and no other differentiating characteristics are salient, by the burden of proof process the actor in the high state $(\mathrm{VC}+)$ is deemed high status and becomes associated with high performance expectations. ${ }^{12}$ Experimental tests by Driskell (1982) confirm this type of generalization process and we propose that a similar process will connect VCs to reward, rather than performance, expectations when no diffuse characteristics are salient. When an offender and victim are not differentiated on race and educational status, if there are differences in appropriate emotional display, we expect referential structures to generate reward expectations consistent with an actor's emotional state. Based on previous research (Heise and Thomas 1989; Lazowski 1987; Tsoudis and Smith-Lovin 1998), such referential structures dictate that remorseful offenders and sad victims (i.e., high status states) deserve high rewards while unemotional offenders and victims (i.e., low status states) warrant low reward levels.

Appendix B illustrates the graph theoretic construction and the calculation of $e$ when the

\footnotetext{
${ }^{12}$ The burden of proof process states that if a status characteristic $i$ ) differentiates actors and $i i$ ) has not been shown to be irrelevant to task, it becomes relevant to the task and is used to as a basis for performance expectations (Berger et al. 1972). Again, see Webster and Foschi (1988) for a full review of generalization process.
} 
victim and offender are differentiated on both diffuse characteristics and VC. For all other combinations of characteristics we perform the calculations following the procedure in Berger et al. (1992). ${ }^{13}$ The expectation advantage measure ranges from -2 to 2 where higher values indicate more numerous positive status characteristics for the offender relative to the victim.

\subsection{Dependent Variables}

Recall that the main explanatory cause of sentencing in the literature is offender dangerousness and offense seriousness. To quantify these variables several survey items were created and then combined to create overall measures of each construct. All questions are measured via a series of nine-point semantic-differential scales, many adapted from measures previously employed by Robinson et al. (1994) and Tsoudis and Smith-Lovin (1998).

To measure offender dangerousness five items using "not" or "very" as the anchors of the scales were administered. Specifically, subjects were asked (i) How likely is it that the offender will commit this crime in the future?, (ii) How often do you think the offender has driven while intoxicated before?, (iii) How likely is it that the offender will commit a white collar crime (e.g. embezzlement, tax evasion, computer fraud) in the future?, (iv) How likely is it that the offender will commit a street crime (e.g. shoplifting, vandalism, assault) in the future?, and (v) In your opinion how likely is it that the offender generally obeys the law?

Offense seriousness was also measured with five items anchored by "not at all" and “extremely." Subjects were asked (i) How outraged are you by the crime against the victim?, (ii) How much has society suffered as a result of the crime against the victim?, (iii) How insulting was the crime against the victim?, (iv) How disrespectful was the crime against the victim?, and (v) How offensive was the crime against the victim?

Based on our argument regarding expectation advantage we hypothesize:

\footnotetext{
${ }^{13}$ These additional combinations include: 1) no D or VC differences (i.e., equal status), and 2) D differences only.
} 
H1: The larger the offender's expectation advantage the less dangerous they will be evaluated.

H2: The larger the offender's expectation advantage the less severe their crime will be evaluated.

Finally, we provide ancillary analysis regarding the sentence a participant would recommend. Recommended sentence is measured by three items specified in years: $(i)$ What sentence would you recommend?, (ii) What is the minimum sentence you would agree upon?, and (iii) What is the maximum sentence you would agree upon? As discussed in section 1, it is assumed that evaluations of offender dangerousness and offense seriousness affect sentencing outcomes. Subjects were not given any guidelines with respect to usual sentences for this type of crime. Consistent with the criminological literature we hypothesize:

H3: The more dangerous an offender is evaluated the longer their recommended sentence.

H4: The more severe an offender's crime is evaluated the longer their recommended sentence.

Although SCT in evaluative settings with valued personal characteristics offers no direct conclusions about how expectation advantage may affect sentencing, we conduct an ancillary analysis of sentencing with regard to our variables of interest. Assuming that status and emotions (as captured by expectation advantage, $e$ ) operate similarly on sentencing as they do on evaluations of offender dangerousness and offense seriousness, we offer the following hypothesis:

H5: The larger the offender's expectation advantage the lower the recommended sentence.

To test our hypotheses requires the aggregation of our survey items for each dependent variable. Using standard criteria in factor analysis we first confirmed that the items for each 
index do load on a single factor. ${ }^{14}$ Additionally, we required each factor to have at least three significant measurement items. Survey items were retained in each factor if $(i)$ the item's factor loading was at least .40 , and (ii) the item-to-total correlation was close to $.50 .{ }^{15}$ For all variables, all questions were included with the exception of question 5 measuring the emotion of the victim. ${ }^{16}$ The overall levels of reliability, as measured by Cronbach's $\alpha$, are within conventional standards for all of our variables (above .70, see Hatcher 1994).

We then indexed the survey items to created composite variables following the procedure outlined in Starkweather (2012). The survey responses are aggregated for each variable using factor scores, the factor loadings for each item, and the weighted mean and weighted standard deviation of the original responses for each item. This process rescales the composite variables back to the original measurement units. Therefore, this process ultimately yields a composite variable that can be interpreted using the original meaning of our Likert scales and is also weighted to reflect the differing levels of significance of each measurement item used in constructing our variables. Table C.1 of the appendix lists the Cronbach's $\alpha$ for each composite variable as well as its mean and standard deviation.

\subsection{Control Variables}

Previous literature suggests that an individual's race and gender may influence their evaluations of criminals and their behaviors, particularly with regard to sentencing (Dane and Wrightsman 1982; Egbert et al. 1992; Moore et al. 1994; Wuensch et al. 2002). In addition, how serious an individual believes a crime to be affects several of their reactions to that crime

\footnotetext{
${ }^{14}$ In order to be deemed significant, a factor had to have an eigenvalue greater than one and explain more than 20 percent of the variance.

${ }^{15}$ See for example Hair et al. (1998), Hatcher (1994), Johnson (1996) and Sharma (1996) for variations of these criteria.

${ }^{16}$ In part due to the open ended nature in which we asked for sentencing recommendations each item was distributed highly non-normally. Therefore, we used the natural logarithm of each item before performing factor analysis.
} 
including the likelihood they will report the behavior to the police (Skogan 1984) and their beliefs about the appropriate penalty (Blumstein and Cohn 1980; Hamilton and Rytina 1980). ${ }^{17}$ There is also justification for including these types of control variables from the SCT literature. Foschi, Lai and Sigerson (1994, p. 328) argue that "in the self-and-two-others setting, factors other than performers' status could affect self's responses." These researchers go on to control for the gender of the individual evaluator in their setting and find significant gender effects in evaluations of performer competency (Foschi, Lai and Sigerson 1994). Therefore throughout our empirical models we control for the race, gender and seriousness beliefs of our participants. In what follows, race is dichotomized into white and nonwhite categories and seriousness belief is measured by a single survey item asking subjects to rate, on a scale of 1 to 9 , "How serious of a crime do you think drunk driving is?"

\section{Results}

\subsection{Manipulation Checks}

Before proceeding to our empirical models we verify that our vignettes had the intended impact. We use a series of $t$-tests to assess the differences in means across survey items to determine that subjects did differentiate between high and low status and emotional and nonemotional offender and victims. The $t$-tests reported in Tables C.2 and C. 3 of Appendix C indicate that for all items related to status and emotion, the mean response and the direction is significantly different for both the offender and victim signifying that subjects correctly perceived the differences in the levels status and emotion as we intended.

\subsection{Expectation Advantage, Offender Dangerousness, Offense Seriousness and Sentencing}

The series of OLS regression models in Table 1 directly test our primary hypotheses related to the impact of offender expectation advantage on the evaluations of offender dangerousness

\footnotetext{
${ }^{17}$ See Warr (1989) for a thorough definition and discussion of perceived crime seriousness.
} 
and offense severity. Recall that Hypotheses 1 and 2 predict that the larger an offender's expectation advantage, the lower their evaluations of offender dangerousness and offense severity, respectively. As predicted, the negative coefficients in Models 1 and 2 show that as the expectation advantage of offenders relative to victims increases the less dangerous they are perceived and the less serious their criminal behavior is evaluated. Both these findings are statistically significant.

Models 1 and 2 provide support that expectation advantage between an offender and victim is affecting the evaluations of criminals and their behavior. As mentioned above, offender dangerousness and offense severity are intermediate steps in the criminal sentencing process. In Model 3 we confirm the standard hypotheses, $H 3$ and $H 4$, that as evaluations of an offender's dangerousness and the severity of their crime increase so too does the sentence that is recommended.

Although SCT offers no direct conclusions about how expectation advantage might directly impact punishment through sentencing, we speculated an additional hypothesis, $H 5$, as an ancillary analysis of subjects recommended sentence. Recall $H 5$ stated that increasing an offender's expectation advantage would decrease the sentence recommended. We do not find any support, as Model 4 indicates, that expectation advantage influences sentencing recommendations. Our results show that status differences between offender and victim clearly affect the antecedents of sentencing but not sentencing recommendations directly.

[Table 1 about here]

\section{Discussion}

The purpose of this research is to determine if status characteristics theory offers any explanatory leverage to understand how relative status differences between offenders and victims 
impact two key focal concerns in criminal sentencing: evaluations of offender dangerousness and offense severity. We argue that these evaluations are affected by status differences determined by the diffuse status and valued personal characteristics of offender and victim. SCT provides a theoretical mechanism to aggregate these characteristics into a single expectation advantage that captures the relative differences in the offender-victim dyad. Our primary assertion is that the more status differentiated the offender-victim dyad, the larger the impact on evaluations. We test our hypotheses in an evaluative setting using data from a vignette study wherein the diffuse status characteristics of race and education as well as the valued personal characteristic of appropriate emotional display by both the offender and victim were varied. Subjects read court testimony from a case of drunk driving where the offender's actions left the victim confined to a wheelchair. Subjects answered a series of questions evaluating the criminal and their behavior.

We first predicted that as the offender's expectation advantage over their victim increased (decreased), evaluations of the dangerousness of the offender and the severity of their crime would decrease (increase). Our results support this hypothesis. As predicted, high status perpetrators who harm low status victims are seen as less criminally dangerous and their crime is assessed as less severe than low status offenders who perpetrate crimes against high status victims. In our vignette conditions, the greatest expectation advantage was between white, highly educated and remorseful offenders and black, lower educated victims who showed no emotion. Accordingly, these offender-victim dyads produced the lowest evaluations of offender dangerousness and offense severity. In contrast, the most highly dangerous criminals and the most severe crimes were perpetrated against white, educated victims who were visibly upset during testimony by black, uneducated offenders who refrained from emotional displays. These offender-victim dyads had expectation advantages favoring the victim over the offender. We 
also speculated, but found no support, that offender's expectation advantage significantly affected recommended sentence.

These results have several implications not only for theory and research in the SCT program and its application to criminological phenomena but for more general studies of sentencing and its antecedents. First, empirical support for our predictions regarding the effect of expectation advantage suggests that such a measure offers a useful and significant tool for aggregating the various diffuse, specific and valued personal characteristics associated with both victims and offenders, previously shown to affect evaluations of offender dangerousness and offense severity. Furthermore, this theoretical measure is beneficial above and beyond empirical interaction terms since it takes into account relative differences between offenders and victims, an important relationship as shown in offender-victim dyad research. Although such a combined measure is not able to assess the direct impact of a single status characteristic, we do not view this as a disadvantage. In many social contexts, including the criminal justice system, individuals are rarely evaluated on the basis of a single characteristic but rather on the basis of multiple attributes as they naturally exist.

Our findings regarding the role of expectation advantage also have important implications for sentencing research. Much of this research does not explicitly measure the evaluations of offender dangerousness and offense severity and instead make direct links between social characteristics and sentencing outcomes. Therefore, when sentencing research shows that age, race, gender etc. has an effect on sentencing outcomes for similar crimes, this disparity suggests an overt form of discrimination. However, our research shows that these disparities may be the result of indirect processes through which subconscious, culturally-established beliefs about social characteristics, as SCT suggests, affect the antecedents of the sentencing process rather 
than sentencing recommendations directly. Here the term discrimination would be inaccurate in describing sentencing disparities since they may not be the result of overt action but rather arise from the unconscious aggregation of beliefs regarding salient social characteristics of both offenders and victims (see Dilks, Thye and Taylor [2010] for further discussion on SCT and discrimination). Fully understanding where, when and how these implicit biases arise is crucial in creating equality under the law.

The lack of direct significance between expectation advantage and sentencing supports research which argues that sentencing decisions are actually the product of several distinct decisions which may be based upon different criteria. For example, Spohn et al. (1981-1982) argued that sentencing is the product of two decisions: $(i)$ whether or not to incarcerate and (ii) how long to incarcerate. Furthermore, each of these decisions may be based upon different criteria. According to Sutton (1978), offender dangerousness may be the better predictor of incarceration while offense seriousness has a larger impact on length of sentence. Our findings support such a disaggregation of sentencing decisions. Specifically, we found that social and emotional characteristics only affected evaluations of offender dangerousness and offense seriousness but not sentencing. However, it would be premature to conclude that social characteristics only affect sentencing antecedents. It may be the case that when aggregated, demographics only affect the evaluations of dangerousness and seriousness but when disaggregated can not only affect these processes but sentencing decisions as well. Determining the exact steps in sentencing decisions that are and are not affected by social characteristics is a worth-while task for future research.

Second, our model usefully leverages three areas of SCT research, previously unexplored, together and in a criminological context: individual evaluative settings, reward expectations 
theory, and valued personal characteristics. The significance of our findings supports the application of SCT to evaluative settings, which occur outside the original task-oriented focus of Berger et al.'s (1977) theory. Extending the scope of theory is an important theoretical and empirical exercise (Cohen 1989; Wagner 1984; Walker and Cohen 1985). Similarly, we also extend research in reward expectations theory (Berger et al. 1998). With the exception of Melamed (2011), most theoretical and empirical work in this area focuses on task competency and how it is linked to rewards via ability or outcome referential structures. We remove any reference to a task structure or outcome, focus on the activation and impact of categorical referential structures, apply the theory to a criminological and individual evaluating setting, and still find support for the theory's assertions. Lastly, and perhaps most significantly, we find support for Driskell's (1982) concept of valued personal characteristics.

Driskell's (1982) original conception of VCs linked them only to performance expectations and only when they were the sole source of differentiation between two actors. Our framework not only links VCs to reward expectations but also examines their impact when differentiating diffuse status information is available. This latter extension is discussed in Driskell (1982) but never formally tested while the connection to reward expectations is a new endeavor. Driskell (1982) only tests and supports the hypothesis that VCs will produce performance expectations when no other status information is salient. While we reproduce this original finding, we also find support for his untested assertion that VCs provide additional, but not expectation-related, information in status organizing processes. However, because this is the first application of VCs in the presence of diffuse characteristics, there remains the question as to whether or not we correctly modeled the impact of valued personal characteristics relative to diffuse characteristics.

Following from Driskell's recommendation, and as illustrated in Example 2 from Appendix 
B, we modeled VCs as affecting a positivity element which in turn influences goal objects. In the calculation of expectation advantage, VCs enter the equation with the same number of paths as diffuse characteristics which impact reward expectations before goal objects. This operationalization means that VCs will have an equivalent impact on goal objects as diffuse characteristics, albeit through a different mechanism. However, a more detailed examination of our data suggests that this type of model may not be appropriate. For example, we find that evaluations of offender dangerousness are significantly higher in conditions where victims and perpetrators are only differentiated on our $\mathrm{VC}$ as compared to conditions where they are only differentiated by diffuse status characteristics. ${ }^{18}$ Thus it appears that, at least in this setting, participants gave greater weight to VC differences as compared to diffuse status differences, despite theoretical equivalency. This suggests to us that more work should be done to determine the appropriate strength of valued personal characteristics on expectations and outcomes in both the presence and absence of other status markers. ${ }^{19}$

Our result that emotional display differences between offender and victim operate as a VC suggests to us that future investigation of sentencing and its antecedents may need to be

\footnotetext{
${ }^{18}$ Two comparisons lead us to this conclusion. First, we compared the mean evaluation of offender dangerousness for 1) conditions where the offender possessed the positive state of the VC but was equivalent to the victim in terms of $\mathrm{D}(+\mathrm{VC}$, no $\mathrm{D})$ to 2 ) conditions where the offender possessed the positive state of $\mathrm{D}$ but was equivalent to the victim on $\mathrm{VC}(+\mathrm{D}$, no $\mathrm{VC})$. The offender should hold an expectation advantage over the victim in both sets of conditions although based on our graph theoretic calculations, this advantage should be bigger in the latter conditions since two Ds differentiate the victim and offender (race and education) rather than a single VC. However, the mean evaluation for the first set of conditions (+VC, no D) is 3.47 while for the second set of conditions $(+\mathrm{D}$, no $\mathrm{VC})$ the mean is $4.14(p=.04)$. Thus, despite a larger expectation advantage, the perpetrator in the $+\mathrm{D}$, no $\mathrm{VC}$ conditions was seen as more criminal than the offender in the $+\mathrm{VC}$, no D conditions. A similar relationship was found in comparing the opposite conditions, i.e., -VC, no D versus $-\mathrm{D}$, no VC.

${ }^{19}$ This future line of inquiry should include an assessment of how status versus valued personal information is conveyed in experimental manipulations. For instance, the type of information given in the vignettes differed between status characteristics and emotions. In the case of diffuse status characteristics, the manipulations were done via labeling, i.e., "African American male," "high school graduate." In the case of emotions, the manipulations included both labeling (i.e., "unhappy," "relaxed") and behavioral information (i.e., "eyes tearing," "begins to weep," "frowning"). The differences in manipulated information could account for the differences reported in footnote 18. Specifically, the combination of labeling plus behavior may have created a more powerful communication of the VC than the DSC. We thank an anonymous reviewer for suggesting this hypothesis.
} 
complimented with increased attention on the implications of emotions. Relative differences in emotional displays between offenders and victims directly affected the antecedents of sentencing outcomes such that the more (appropriate) emotion displayed by the perpetrator and the less emotion displayed by the victim, the less criminal the offender was evaluated and the less severe their crime. Such a strong effect of emotions should not be ignored and calls for more research to replicate our results. In addition, it is not uncommon for attorneys of both victims and offenders to actively coach their clients as to the appropriate emotions to display during trial and testimony. Such coaching however creates a problem: How do judges and jurors know that displayed emotions are real and not just the result of quality instruction by qualified and resourceful attorneys? Presumably evaluators engage in assessments of the sincerity of such emotional displays but what factors affect this assessment? These issues further complicate the role of emotions, particularly in the sentencing process.

Lastly, our exploration of SCT in evaluations of offender dangerousness and offense severity suggests that SCT may apply in other legal decision making contexts. For example, status processes might affect police discretion to arrest or not arrest individuals or the decision to grant parole to previously convicted criminals. Future research should continue to explore the reach of SCT for understanding other phenomena in criminal justice contexts.

A number of variations in the basic vignette design employed in our research would also do much to expand the understanding of the role of status and emotional displays in evaluations of offender dangerousness and offense severity and the resulting implications for sentencing. First, in terms of status, the current vignette only manipulated two diffuse characteristics: race and education level. Future research could also examine the impact of sex, occupation, and age, along with alternative combinations of these characteristics (e.g., African American, college 
educated, male, and unemployed). Expectation advantage can still be calculated using these varied combinations and resulting analyses could confirm the robustness of our results.

Second, many studies have found that the type of crime committed may have an impact on the saliency of certain factors in evaluations of dangerousness and seriousness (see Spohn and Cederblom [1991] for a review). For instance, Kalven and Zeisel's (1966) liberation theory argues that race only plays a role in less serious crimes. Our vignette study was based on a case of drunk driving which could limit the generalizability of our results to other types of crime. Future studies should vary both the nature and severity of the crime committed.

While our study is concerned with the impact of diffuse and valued personal characteristics on evaluations of dangerousness and crime severity, the effects of more specific legal variables on these evaluations such as weapon use and prior criminal history of the offender that may have facilitated the crime should not be ignored. For example, Spohn (2009) includes data collected by Spohn and DeLone (1996) that show that increases in conviction charge severity, the number of prior felony convictions, or the number of prior prison sentences, makes defendants more likely to be sentenced to prison for longer periods of time. Other studies include similar legal variables as controls but continue to find that they significant affect sentencing outcomes (e.g., Albonetti 2002; Kramer and Ulmer 2002; Steffensmeier et al. 1998). These important variables can be incorporated in the SCT framework and the calculation of expectation advantage with the challenge resulting from should a particular variable operate as a specific or diffuse characteristic. For example, prior criminal record may suggest a specific characteristic where whether a weapon was used or not may operate as a diffuse characteristic.

Our research applies new theory to an actively studied area of criminological inquiry in an attempt to expand our knowledge of the effects of status variables and emotional displays on the 
antecedents of sentencing decisions. We present a formulation that provides a theoretical integration of some of the important prior empirical research in this area, and in turn relate it to status phenomena that are accountable by status characteristics theory and several of its extensions. Specifically, the application of SCT contributes an aggregative and relative measure to criminological research that takes into consideration the overall status differences between offenders and victims involved in a crime. Measures of offender/victim expectation advantage provide researchers with a concise method for incorporating a diversity of factors shown to impact evaluations of offender dangerousness and offense severity and may also inform other legal evaluations. A theoretical approach that captures the myriad of social, emotional and legally-relevant information that could influence these decision making processes should have wide-ranging appeal. 


\section{References}

Albonetti, Celesta A. 1991. "An Integration of Theories to Explain Judicial Discretion.” Social Problems 38(2):247-266.

-----. 1997. "Sentencing Under the Federal Sentencing Guidelines: Effects of Defendant

Characteristics, Guilty Pleas, and Departures on Sentence Outcomes for Drug Offenses, 1991-1992." Law \& Society Review 31:789-822.

-----. 2002. “The Joint Conditioning Effect of Defendants' Gender and Ethnicity on Length of Imprisonment Under the Federal Sentencing Guidelines for Drug Trafficking/Manufacturing Offenders." The Journal of Gender, Race \& Justice 6:39-60.

Baldus, David C., George G. Woodworth, and Charles A Pulaski Jr. 1990. Equal Justice and the Death Penalty: A Legal and Empirical Analysis. Boston: Northeastern University Press. Bales, Robert F. 1953. “The Equilibrium Problem in Small Groups.” Pp. 111-61 in Working Papers in the Theory of Action, edited by T. Parsons, R. F. Bales, and E. H. Shils. Glencoe, IL: Free Press.

Balkwell, James W. 1991. "Status Characteristics and Social Interaction.” Pp. 135-76 in Advances in Group Processes, edited by Edward J. Lawler, Barry Markovsky, Cecilia Ridgeway, and Henry A. Walker. Greenwich, CT: JAI.

----. 2000. “Calculating an Actor's Expectation State Value.'” Retrieved from http://www.geocities.com/jwbalkwell/expect.html.

Baumer, E. P., S.F. Messner, and R.B. Felson. 2000. "The Role of Victim Characteristics in the Disposition of Murder Cases.” Justice Quarterly 17:281-307. 
Berger, Joseph and Murray Webster Jr. 2006. Expectations, Status, and Behavior. Pp. 268-300 in Contemporary Social Psychological Theories edited by Peter J. Burke. Stanford: Stanford University Press.

Berger, Joseph, Bernard P. Cohen, and Morris Zelditch, Jr. 1972. "Status Characteristics and Social Interaction.” American Sociological Review 37:241-255.

Berger, Joseph, Thomas L. Conner and M. Hamit Fisek. 1974. Expectation States Theory: A Theoretical Research Program. Cambridge, MA: Winthrop.

Berger, Joseph, M. Hamit Fisek, Robert Z. Norman, and David Wagner. 1998. "Formation of Reward Expectations in Status Situations.” Pp. 121-153 in Status, Power and Legitimacy, edited by J. Berger and M. Zelditch Jr. New Brunswick, NJ: Transaction Publishers.

Berger, Joseph, M. Hamit Fisek, Robert Z. Norman, and Morris Zelditch, Jr. 1977. Status

Characteristics and Social Interaction. New York: Elsevier.

Berger, Joseph, Robert Norman, James W. Balkwell and Roy F. Smith. 1992. "Status Inconsistency in Task Situations: A Test of Four Status Processing Principles.” American Sociological Review 57:843-855.

Bianchi, Alison J. 2005. "Rejecting Others' Influence: Negative Sentiment and Status in Task Groups." Sociological Perspectives 47:4:339-355.

Bianchi, Alison J. and Donna A. Lancianese. 2007. "Accentuate the Positive: Positive Sentiment and Status in Task Groups." Social Psychological Quarterly 70:1:7-26.

Black, Donald. 1976. The Behavior of Law. New York: Academic Press.

Blumstein, Alfred and Jacqueline Cohn. 1980. "Sentencing of Convicted Offenders: An Analysis of the Public's View." Law and Society Review 14:233-261. 
Blumstein, Alfred, Jacqueline Cohen, Susan E. Martin and Michael H. Tonry. 1983. Research on Sentencing: The Search for Reform. Washington, DC: National Academy Press.

Bridges, George S. and Robert D. Crutchfield. 1988. "Law, Social Standing, and Racial Disparities in Punishment.” Social Forces 66:699-724.

Bridges, George and Sara Steen. 1998. "Racial Disparities in Official Assessments of Juvenile Offenders: Attributional Stereotypes as Mediating Mechanisms." American Sociological Review 63(4): 554-570.

Byrne, D. 1971. The Attraction Paradigm. New York: Academic Press.

Cohen, Bernard P. 1989. Developing Sociological Knowledge: Theory and Method. 2nd edition. Chicago: Nelson-Hall.

Cohen, Elizabeth G. and Susan S. Roper. 1972. "Modification of Interracial Interaction Disability: An Application of Status Characteristics Theory." American Sociological Review $37: 643-657$

Correll, Shelley J. 2001. "Gender and the Career-Choice Process: The Role of Biased SelfAssessments.” American Journal of Sociology 106:1691-1730.

Correll, Shelley J. 2004. "Constraints into Preferences: Gender, Status and Emerging Career Aspirations." American Sociological Review 69:93-133.

Correll, Shelley J. and Cecilia L. Ridgeway. 2003. "Expectation States Theory.” Pp. 29-51 in The Handbook of Social Psychology, edited by J. Delamater. New York: Kluwer Academic Press.

Curry, Theodore R., Gang Lee and S. Fernando Rodriguez. 2004. "Does Victim Gender Increase Sentence Severity? Further Explorations of Gender Dynamics and Sentencing Outcomes." Crime \& Delinquency 50:319-343. 
Dane, F. C. and L.S Wrightsman. 1982. 'Effects of Defendants' and Victims' Characteristics on Jurors' Verdicts.” Pp. 83-111 in The Psychology of the Courtroom, edited by N. L. Kerr and R. M. Bray. San Diego, CA: Academic Press.

Demleitner, Nora V., Douglas A. Berman, Marc L. Miller and Ronald F. Wright. 2004. Sentencing Law and Policy: Cases, Statutes, and Guidelines. New York: Aspen Publishers.

Dilks, Lisa M., Shane R. Thye, and Patricia A. Taylor. 2010. "Socialization Economic Theories of Discrimination: Lessons from Survivor.” Social Science Research 39:1164-1180.

Drass, Kriss A. and J. William Spencer. 1987. “Accounting for Sentencing Recommendations: Typologies and Probation Officers' Theory of Office.” Social Problems 34:1059-1075.

Driskell, James E. 1982. "Personal Characteristics and Performance Expectations." Social Psychology Quarterly 45:229-237.

Driskell, James E. and Murray Webster Jr. 1997. “Status and Sentiment in Task Groups.” Pp. 179-200 in Status, Network, and Structure: Theory Development in Group Processes, edited by J. Szmatka, J. Skvoretz, and J. Berger. Stanford, CA: Stanford University Press. Egbert, J. M., C. H. Moore, K. L. Wuensch and W. A. Castellow. 1992. “The Effect of Litigant Social Desirability on Judgments Regarding a Sexual Harassment Case.” Journal of Social Behavior and Personality 7:569-579.

Eisenberg, Nancy. 2000. "Emotion, Regulation, and Moral Development." Annual Review of Psychology 51:665-697.

Erickson, K.G. 1998. The Impact of Cultural Status Beliefs on Individual Task Performance in Evaluative Settings: A New Direction in Expectation States Research. Ph.D. Dissertation. Stanford University: Department of Sociology. 
Farrell, R. A. and V.L. Swigert. 1986. "Adjudication in Homicide: An interpretive Analysis of the Effects of Defendant and Victim Social Characteristics." Journal of Research in Crime and Delinquency 23:349-369.

Fearn, N. E. 2005. “A Multilevel Analysis of Community Effects on Criminal Sentencing.” Justice Quarterly 22(4):452-487.

Ferrell, M.,W. Tolone and R. Walsh. 1977. "Maturational and Societal Change in the Sexual Double-Standard: A Panel Analysis (1967-1971; 1970-1974).” Journal of Marriage and Family 36:255-272.

Fisek, M. Hamit and Joseph Berger. 1998. "Sentiment and Task Performance Expectations." Advances in Group Processes 15:23-39.

Fisek, M. Hamit and Stuart J. Hysom. 2008. "Status Characteristics and Reward Expectations: A Test of a Theory of Justice in Two Cultures.” Social Science Research 37:769-786.

Fletcher, George P. 2000. Rethinking Criminal Law. New York: Oxford University Press:

ForsterLee, L., G.B. Fox, R. ForsterLee, and R. Ho. 2004. "The Effects of Victim Impact Statement and Gender on Juror Information Processing in a Criminal Trial: Does the Punishment Fit the Crime?" Australian Psychologist 39(1):57-67.

Foschi, Martha. 1989. "Status Characteristics, Standards and Attributions.” Pp. 58-72 in Sociological Theories in Progress: New Formulations, edited by J. Berger, M. Zelditch, Jr., and B. Anderson. Newbury Park: Sage Publications.

Foschi, Martha. 2000. "Double Standards for Competence: Theory and Research.” Annual Review of Sociology 26:21-42.

Foschi, Martha, Larissa Lai, and Kirsten Sigerson. 1994. "Gender and Double Standards in the Assessment of Job Applicants.” Social Psychology Quarterly 57:326-339. 
Franklin, Cortney and Noelle Fearn. 2008. “Gender, Race, and Formal Court Decision-Making Outcomes: Chivalry/Paternalism, Conflict Theory or Gender Conflict?" Journal of Criminal Justice 36(3):279-290.

Freese, Lee. 1974. “Conditions for Status Equality in Formal Task Groups.” Sociometry 37:174188.

Freiburger, Tina L., Catherine D. Marcum and Mari Pierce. 2010. "The Impact of Race on the Pretrial Decision.” American Journal of Criminal Justice 35:76-86.

Hair, J.F. Jr. , Anderson, R.E., Tatham, R.L., \& Black, W.C. 1998. Multivariate Data Analysis, (5th edition). Upper Saddle River, NJ: Prentice Hall.

Hamilton, V. Lee and Steve Rytina. 1980. "Social Consensus on Norms of Justice: Should the Punishment Fit the Crime?” American Journal of Sociology 85:1117-1144.

Hatcher, L. 1994. A Step-by-Step Approach to Using the SAS System for Factor Analysis and Structural Equation Modeling. Cary, NC: SAS Institute Inc.

Heider, Fritz. 1958. The Psychology of Interpersonal Relations. New York: Wiley.

Heise, David R. and Lisa Thomas. 1989. "Predicting Impressions Created by Combinations of Emotion and Social Identity." Social Psychology Quarterly 42:141-148.

Hembroff, Larry A. 1982. "Resolving Status Inconsistency: An Expectation States Theory and Test." Social Forces 61(1):183-205.

Hochschild, Arlie R. 1979. "Emotion Work, Feeling Rules, and Social Structure.” American Journal of Sociology 85:551-575.

----- 1983. The Managed Heart: Commercialization of Human Feeling. Berkeley, CA: University of California Press. 
Holcomb, J. E., M.R. Williams and S. Demuth. 2004. "White Female Victims and Death Penalty Disparity Research.” Justice Quarterly 21:877-902.

Holleran, David and Cassia Spohn. 2004. "On the Use of the Total Incarceration Variable in Sentencing Research.” Criminology 42(1):211-240.

Houser, Jeffrey A. and M. Lovaglia. 2002. "Status, Emotion and the Development of Solidarity in Stratified Task Groups.” Advances in Group Processes 19:109-137.

Humphreys, Paul and Joseph Berger. 1981. "Theoretical Consequences of the Status Characteristics Formulation." American Journal of Sociology 86:958-983.

Hunter, R. J., P. H. Ralph and J. Marquart. 1993. “The Death Sentencing of Rapists in PreFurman Texas (1942 to 1971): The Racial Dimension." American Journal of Criminal Law 20:313-337.

Hysom, Stuart J. 2009. "Status Valued Goal Objects and Performance Expectations." Social Forces 87:1623-1648.

Hysom, Stuart J. and M. Hamit Fisek. 2011. "Situational Determinants of Reward Allocation: The Equity-Equality Equilibrium Model.” Social Science Research 40:1263-1285.

Johnson, D.E. (1998). Applied Multivariate Methods for Data Analysis. Pacific Grove, CA: Brooks/Cole Publishing.

Johnson, R.A. \& Wichern, D.W. (2002). Applied Multivariate Statistical Analyses (5th edition). Upper Saddle River, NJ: Prentice Hall.

Johnson, Brian D., Sigrid Van Wingerden and Paul Nieuwbeerta. 2010. "Sentencing Homicide Offenders in the Netherlands: Offender, Victim, and Situational Influences in Criminal Punishment." Criminology 48(4):981-1018. 
Kalkhoff, Will and Shane R. Thye. 2006. "Expectation States Theory and Research:

New Observations from Meta-Analysis.” Sociological Methods and Research 35:219249.

Kalven, Harry Jr. and Hans Zeisel. 1966. The American Jury. Boston, MA: Little Brown \& Company.

Karasawa, Kaori. 1995. "An Attributional Analysis of Reactions to Negative Emotions." Personality and Social Psychology Bulletin 21: 456-467.

Kautt, Paula. 2009a. "Is the Offense Axis Free of Extralegal Influence?: Assessing the Predictors of a 'Legally Relevant' Guidelines Criterion.” American Journal of Criminal Justice 34:253273.

-----. 2009b. "Heuristic Influences Over Offense Seriousness Calculations: A Multilevel Investigation of Racial Disparity Under Sentencing Guidelines.” Punishment \& Society $11: 191-218$

Kautt, Paula and Cassia. Spohn. 2002. "Cracking Down on Black Drug Offenders? Testing for Interactions between Offender Race, Drug Type, and Sentencing Strategy in Federal Drug Sentences.” Justice Quarterly 19(1):1-35.

Kelley, Christopher P., Christabel L. Rogalin, Shane D. Soboroff, Jeffrey W. Lucas, and Michael J. Lovaglia. 2009. "Status, Prestige and Expected Value in Work Settings: The Age-Gender Interaction." Presented at the Annual Meetings of the American Sociological Association. San Francisco, CA.

Kingsnorth, R., R. MacIntosh, and J. Wentworth. 1999. "Sexual Assault: The Role of Prior Relationship and Victim Characteristics in Case Processing." Justice Quarterly 16:275302. 
Kingsnorth, Rodney, John Lopez, Jennifer Wentworth and Debra Cummings. 1998. “Adult Sexual Assault: The Role of Racial/Ethnic Composition in Prosecution and Sentencing." Journal of Criminal Justice 26(5):359-371.

Kingsnorth, R., R. MacIntosh, T. Berdahl, C. Blades and S. Rossi. 2001. "Domestic Violence: The Roles of Interracial/Ethnic Dyads in Criminal Court Processing." Journal of Contemporary Criminal Justice 17:123-141.

Kramer, John H. and Darrell Steffensmeier. 1993. "Race and Imprisonment Decisions.” The Sociological Quarterly 34:357-376.

Kramer, John H. and Jeffery Ulmer. 2002. “Downward Departures for Serious Violent Offenders: Local Court 'Corrections’ to Pennsylvania's Sentencing Guidelines.” Criminology 40: 897-932.

LaFree, Gary. 1980. "The Effect of Sexual Stratification by Race on Official Reactions to Rape." American Sociological Review 45:842-854.

Lazowski, Linda E. 1987. Speakers' Nonverbal Expressions of Emotion as Moderators of Listeners' Reactions to Disclosures of Self Harm and Social Harm. Ph.D. dissertation. University of California, Santa Barbara: Department of Sociology.

Lee, R.Y.-P. and M.H. Bond. 1996. "How Friendship Develops Out of Personality and Values: A Study of Interpersonal Attraction in Chinese Culture." Unpublished Manuscript, Chinese University of Hong Kong.

Lockheed, M.E. and K.P. Hall. 1976. "Conceptualizing Sex as a Status Characteristic: Applications to Leadership Training Strategies.” Journal of Social Issues 32:111-124. Lovaglia, Michael J., and Jeffrey Houser. 1996. "Emotional Reactions and Status in Groups." American Sociological Review 61:867-83. 
Lovaglia, Michael J., Jeffrey W. Lucas, Jeffery A. Houser, Shane R. Thye, and Barry Markovsky. 1998. "Status Processes and Mental Ability Test Scores.” American Journal of Sociology 104:195-228.

Mackinnon, S.P., C.H. Jordan and A.E. Wilson. 2011. "Birds of a Feather Sit Together: Physical Similarity Predicts Seating Choice.” Personality and Social Psychology Bulletin 37:879-892. Markovsky, Barry, Joseph Berger, and LeRoy Smith. 1984. "Do Status Interventions Persist?" American Sociological Review 49:373-382.

Martin, Christine. 2013. “Conviction Odds in Chicago Homicide Cases: Does Race/Ethnicity Matter?" Journal of Ethnicity in Criminal Justice 11(1-2):22-43.

Meeker, Barbara F. and Patricia A. Weitzel-O’Neill. 1977. “Sex roles and Interpersonal Behavior in Task Oriented Groups.” American Sociological Review 42:92-105.

Melamed, David. 2011. "Graded Status Characteristics and Expectation States.” Pp. 1-31 in Advances in Group Processes, Vol. 28, edited by S. Thye and E. Lawler. Cambridge, MA: Emerald Group.

Miethe, Terance D. and Charles A. Moore. 1986 "Racial Differences in Criminal Processing: The Consequences of Model Selection on Conclusions about Differential Treatment." The Sociological Quarterly 27:217-237.

Mikula G, Scherer KR, and U. Athenstaedt 1998. "The Role of Injustice in the Elicitation of Differential Emotional Reactions.” Personality and Social Psychology Bulletin 24:769783.

Moore, C.A. and T.D. Miethe. 1986 "Regulated and Unregulated Sentencing Decisions: An Analysis of First Year Practices under Minnesota's Felony Sentencing Guidelines.” Law and Society Review 20(2): 253-277. 
Moore, C. H., K. L. Wuensch, R. M. Hedges, and W. A. Castellow. 1994. "The Effects of Physical Attractiveness and Social Desirability on Judgments Regarding a Sexual Harassment Case." Journal of Social Behavior and Personality 9:715-730.

Myers, M. A. and G.D LaFree. 1982. "Sexual Assault and its Prosecution: A Comparison with Other Crimes." Journal of Criminal Law and Criminology 73:1282-1305.

Newcomb, T.M. 1961. The Acquaintance Process. New York: Holt, Rinehart \&Winston.

Niedermeier, Keith E., Irwin A. Horowitz, and Norbert L. Kerr. 1999. “Informing Jurors of Their Nullification Power: A Route to a Fair Verdict or Judicial Chaos?" Law and Human Behavior 23:331-335.

-----. 2001. "Exceptions to the Rule: The Effects of Remorse, Status, and Gender on Decision Making.” Journal of Applied Social Psychology 31:604-623.

Nobiling, Tracy, Cassia Spohn, and Miriam DeLone. 1998. “A Tale of Two Counties:

Unemployment and Sentence Severity.” Justice Quarterly 15:401-427.

Ridgeway, Cecilia L. 1994. "Affect.” Pp. 205-230 in Group Processes: Sociological Analyses, edited by M.Foschi and E. J. Lawler. Chicago: Nelson-Hall.

Roberts, Aki and Christopher J. Lyons. 2009. "Victim-Offender Racial Dyads and Clearance of Lethal and Nonlethal Assault." Journal of Research in Crime and Delinquency 46(3):301326.

Robinson, Dawn T., Lynn Smith-Lovin and Olga Tsoudis. 1994. "Heinous Crime or Unfortunate Accident? The Effects of Remorse on Responses to Mock Criminal Confessions." Social Forces 73:175-190.

Rose, A. and A. Prell. 1955. "Does the Punishment Fit the Crime? A Study in Social Valuation." American Journal of Sociology 75:309-322. 
Rumsey, M.G. 1976. "Effects of Defendant Background and Remorse on Sentencing Judgments." Journal of Applied Social Psychology 6: 64-68.

Scher S.J. 1997. "Measuring the Consequences of Injustice.” Personality and Social Psychology Bulletin 23:482-497.

Selby, J.W., L.G. Calhoun and T.A. Brock. 1977. "Sex Differences in the Social Perception of Race Victims." Personality and Social Psychology Bulletin 3:412-415.

Sharma, S. (1996). Applied Multivariate Techniques. Hoboken, NJ: John Wiley \& Sons.

Shelly, Robert K. 2001. "How Performance Expectations Arise from Sentiments.” Social Psychology Quarterly 64(1):72-87.

Skogan, Wesley G. 1984. "The Validity of Official Crime Statistics: An Empirical Evaluation.” Social Science Quarterly 55:25-38.

Spencer, Jack W. 1983. “Accounts, Attitudes and Solutions: Probation-Officer-Defendant Negotiations of Subjective Orientations.” Social Problems 30:570-581.

Spohn, Cassia. 2009. How Do Judges Decide? The Search for Fairness and Justice in Punishment. Thousand Oaks, CA: Sage.

Spohn, Cassia and Jerry Cederblom. 1991. "Race and Disparities in Sentencing: A Test of the Liberation Hypothesis.” Justice Quarterly 8:601-623.

Spohn, Cassia and Miriam DeLone. 1996. "A Multi-Site Study of the Effect of Race on Sentencing." Unpublished data.

Spohn, Cassia and David Holleran. 2000. "The Imprisonment Penalty Paid by Young, Unemployed Black and Hispanic Offenders." Criminology 38:281-306.

Spohn, Cassia, John Gruhl, and Susan Welch. 1981-82. "The Effect of Race on Sentencing: A Re-examination of an Unsettled Question.” Law \& Society Review 16:71-88. 
Starkweather, Jon. 2012. "How to Calculate Empirically Derived Composite or Indicator Scores.” Retrieved from Benchmarks Online: http://web3.unt.edu/benchmarks/issues/2012/02/rss-matters.

Steele, Claude M. 1997. "A Threat is in the Air: How Stereotypes Shape Intellectual Identity and Performance." American Psychologist 52:613-629.

Steen, S., R.L. Engen and R.R. Gainey. 2005. "Images of Danger and Culpability: Racial Stereotyping, Case Processing and Criminal Sentencing." Criminology 43(2): 435-467. Steffensmeier, Darrell. 1977. "The Effects of Judge's and Defendant's Sex on the Sentencing of Offenders." Psychology: A Journal of Human Behavior 14:3-9.

-----. 1980. “Assessing the Impact of the Women's Movement on Sex-based Differences in the Handling of Adult Criminal Defendants." Crime and Delinquency 26:344-357.

Steffensmeier, Darrell and Stephen Demuth. 2000. "Ethnicity and Sentencing Outcomes in U.S. Federal Courts: Who is Punished More Harshly?" American Sociological Review 65:705729.

----. 2001. “Ethnicity and Judges' Sentencing Decisions: Hispanic-Black-White Comparisons.” Criminology 39:145-178.

-----. 2006. “Does Gender Modify the Effects of Race-ethnicity on Criminal Sentencing? Sentences for Male and Female White, Black and Hispanic Offenders.” Journal of Quantitative Criminology 22:241-261.

Steffensmeier, Darrell and John H. Kramer. 1982. "Sex-Based Differences in the Sentencing of Adult Criminal Defendants: An Empirical Test and Theoretical Overview." Sociology and Social Research 66:289-304. 
Steffensmeier, Darrell, John H. Kramer, and Cathy Streifel. 1993. "Gender and Imprisonment Decisions." Criminology 31:411-446.

Steffensmeier, Darrell, Jeffery Ulmer, and John Kramer. 1998. "The Interaction of Race, Gender and Age in Criminal Sentencing: The Punishment Cost of Being Young, Black and Male.” Criminology 36:763-797.

Stephan, C. 1975. "Selective Characteristics of Jurors and Litigants: Their Influences on Juries' Verdicts.” Pp. 95-122 in The Jury System in America, edited by R. J. Simon. Beverly Hills: Sage.

Stets, Jan E. "Emotions and Sentiments." Pp. 309-335 in Handbook of Social Psychology, edited by John DeLamater. New York: Kluwer Academic/Plenum.

Sutton, L. Paul. 1978. Federal Sentencing Patterns: A Study of Geographical Variations. Albany, NY: Criminal Justice Research Center.

Thoits, Peggy A. 1990. "Emotional Deviance: Research Agendas.” Pp. 180-203 in Research Agendas in the Sociology of Emotions, edited by T. D. Kemper. Albany, NY: State University of New York Press.

Tsoudis, Olga and Lynn Smith-Lovin. 1998. "How Bad Was It? The Effects of Victim and Perpetrator Emotion on Responses to Criminal Court Vignettes.” Social Forces 77:695-722. Towson, S.M.J. and M.P. Zanna. 1983. "Retaliation Against Sexual Assault: Self-Defense or Public Duty?" Psychology of Women Quarterly 8:89-99.

Ugwuegbu, J.E. 1979. "Racial and Evidential Factors in Juror Attribution of Legal Responsibility." Journal of Experimental Social Psychology 15:133-146.

Ulmer, Jeffery T. 1997. Social Worlds of Sentencing: Court Communities Under Sentencing Guidelines. Albany NY: SUNY Press. 
Ulmer, Jeffery T. and B. Johnson. 2004. "Sentencing in Context: A Multilevel Analysis." Criminology 42:137-178.

Unnever, James D. 1982. "Direct and Organizational Discrimination in the Sentencing of Drug Offenders." Social Problems 30:212-225.

Unnever, James D. and Larry A. Hembroff. 1988. "The Prediction of Racial/Ethnic Sentencing Disparities: An Expectation States Approach." Journal of Research in Crime and Delinquency 25:53-82.

Wagner, David G. 1984. The Growth of Sociological Theories. Beverly Hills, CA: Sage.

Wagner, David. G. 1995. "Gender Differences in Reward Preference: A Status-Based Account." Small Group Research 26:353-371.

Walker, Henry A., and Bernard P. Cohen. 1985. "Scope Statements: Imperatives for Evaluating Theory." American Sociological Review 50:288-301.

Walsh, A. 1987. "The Sexual Stratification Hypothesis and Sexual Assault in Light of Changing Conceptions of Race." Criminology 25:153-173.

Warr, Mark. 1989. "What is the Perceived Seriousness of Crimes?” Criminology 27:795-821.

Webster, Murry, Jr., and James E. Driskell, Jr. 1978. "Status Generalization: A Review and Some New Data" American Sociological Review 43:220-236.

-----. 1983. “Processes of Status Generalization.” Pp. 57-68 in Small Groups and Social Interaction, Vol. 1, edited by H.H. Blumberg, A.P. Hare, V. Kent and M. Davies. London: John Wiley and Sons.

Webster, Murray Jr. and Martha Foschi. 1988. “Overview of Status Generalization.” Pp. 1-20 and 477-478 in Status Generalization: New Theory and Research, edited by M. Webster, Jr. and M. Foschi. Stanford: Stanford University Press. 
Webster, Murray, Jr. and Stuart J. Hysom. 1998. "Creating Status Characteristics.” American Sociological Review 63:351-378.

Webster, Murray, Jr., Stuart J. Hysom and Elise M. Fullmer. 1998. "Sexual Orientation and Occupation as Status." Advances in Group Processes 15:1-21.

Wuensch, Karl L., Matthew W. Campbell, Frederick C. Kesler, and Charles H. Moore. 2002. "Racial Bias in Decisions Made by Mock Jurors Evaluating a Case of Sexual Harassment." The Journal of Social Psychology 142(5):587-600.

Yankah, Ekow N. 2003-2004. "Good Guys and Bad Guys: Punishing Character, Equality and the Irrelevance of Moral Character to Criminal Punishment.” Cardozo Law Review 25(3):1019-1067.

Zatz, Marjorie S. 1984. "Race, Ethnicity, and Determinate Sentencing." Criminology 22:147171.

-----. 1985. "Pleas, Priors, and Prison: Racial/Ethnic Differences in Sentencing." Social Research 14:169-193.

Zelditch, Morris, Jr. Patrick Lauderdale, and Steve Stublarec. 1980. "How are Inconsistencies between Status and Ability Resolved?" Social Forces 58:1025-1043. 
Tables

Table 1. Impact of Expectation Advantage on Evaluations of Offender Dangerousness, Offense Severity and Sentencing

\begin{tabular}{|c|c|c|c|c|}
\hline & Model 1 & Model 2 & Model 3 & Model 4 \\
\hline Dependent Variable: & $\begin{array}{c}\text { Offender } \\
\text { Dangerousness }\end{array}$ & $\begin{array}{l}\text { Offense } \\
\text { Severity }\end{array}$ & Sentencing & Sentencing \\
\hline \multicolumn{5}{|l|}{ Independent Variables: } \\
\hline $\begin{array}{l}\text { Offender Expectation } \\
\text { Advantage }(e)\end{array}$ & $\begin{array}{l}-0.27^{*} \\
(0.21)\end{array}$ & $\begin{array}{l}-0.27 * * \\
(0.15)\end{array}$ & ----- & $\begin{array}{c}0.01 \\
(0.02)\end{array}$ \\
\hline Offender Dangerousness & ---- & ----- & $\begin{array}{l}0.04 * * * \\
(0.01)\end{array}$ & ----- \\
\hline Offense Seriousness & ----- & ----- & $\begin{array}{l}0.03 * * \\
(0.01)\end{array}$ & ----- \\
\hline \multicolumn{5}{|l|}{ Control variables: } \\
\hline White & $\begin{array}{l}-0.15 \\
(0.20)\end{array}$ & $\begin{array}{l}-0.12 \\
(0.13)\end{array}$ & $\begin{array}{l}-0.004 \\
(0.04)\end{array}$ & $\begin{array}{l}-0.01 \\
(0.05)\end{array}$ \\
\hline Female & $\begin{array}{c}0.15 \\
(0.15)\end{array}$ & $\begin{array}{c}0.09 \\
(0.12)\end{array}$ & $\begin{array}{l}-0.04 \\
(0.04)\end{array}$ & $\begin{array}{l}-0.03 \\
(0.04)\end{array}$ \\
\hline Seriousness belief & $\begin{array}{l}0.17 * * * \\
(0.07)\end{array}$ & $\begin{array}{l}0.27 * * * \\
(0.05)\end{array}$ & $\begin{array}{l}0.07^{* * *} \\
(0.02)\end{array}$ & $\begin{array}{l}0.08^{* * * *} \\
(0.02)\end{array}$ \\
\hline
\end{tabular}

Notes: Robust standard errors in parentheses. $N=541$ for all models.

$* p<.10 ; * * p<.05 ; * * * p<.01$ (one-tailed tests) 


\title{
Appendix A. Vignette condition for high status/neutral offender and low status/sad victim
}

\author{
Adapted from Robinson et al. (1994) and Tsoudis and Smith-Lovin (1998)
}

The circumstances surrounding a particular legal case appear as follows: John Kemp is a 23year-old white male and a pre-law student in his senior year of college. Recently, John went to a party at a local bar to celebrate his birthday. His friends and family kept John's cup constantly filled with scotch and soda and John became quite drunk. John left the bar at closing time and while driving home ran a stoplight causing a collision with a car in the right-of-way. The driver of the other car was 23-year-old Alex Baker. Alex is an African-American male, works in the service industry, and is a high school graduate. Alex was seriously injured in the accident and has since been confined to a wheelchair.

During the trial, both John, the defendant, and Alex, the victim, took the stand to testify as to the events of that night. Below are transcripts of these statements. The transcriber has added some descriptive passages in italics to help you visualize how John and Alex appeared during the actual testimony.

\section{John's defendant testimony:}

(Relaxed facial expression, sits with arms resting on chair arms, makes eye contact) I left the bar feeling dizzy. I found my car after five minutes of searching. Then I remember dropping the keys and looking for them. Well ... then I got into the car and started driving. Um . . . (makes one on one eye contact) I remember swerving. Um . . once or twice (concentrating). OK, OK . . . maybe three times into the opposite lane. I remember getting back into the correct lane and then things seemed to get a little fuzzy (tilts head to left). Next thing I knew, I had slammed into another car (pause). I got out to help the other driver. Blood was splashed all over the windshield and the inside of his car (leans back in chair). He just laid there (staring straight ahead). I didn't see the other car. I don't know where he came from (blinks three times). I did not see the stoplight (pause). I know I didn't.

\section{Alex, the victim's testimony:}

(Unhappy, in low spirits / hands on lap, fingers intertwined, eyes looking down at lap). I had just left a friend's house and was on my way home. I was at the stoplight about two blocks from my house when (takes in a deep breath) he hit me. I'm sure I had the right-of-way at the light and (head down, eyes looking at the floor) the car came out of nowhere (shakes head four times). I felt the impact and then (lifts head, eyes tearing), I couldn't move (begins to weep). I didn't know what was going on. I didn't know what to do (weeping, one hand on face). The next thing I knew (eyes red) I woke up in the hospital. The nurse told me I had been hit by another car. I was there for about (frowning, takes two deep breaths) two months. Now I am back home (continuous sniffling, looking down). I am in a wheelchair and the doctors are certain I'll be in it for the rest of my life. 
Appendix B. Graph Theoretical Representation of Appropriate Emotional Display as VC

Differentiation by Appropriate Emotional Display and Two Diffuse Status Characteristics - White, Educated, Remorseful Offender and Black, Uneducated, Non-emotional Victim

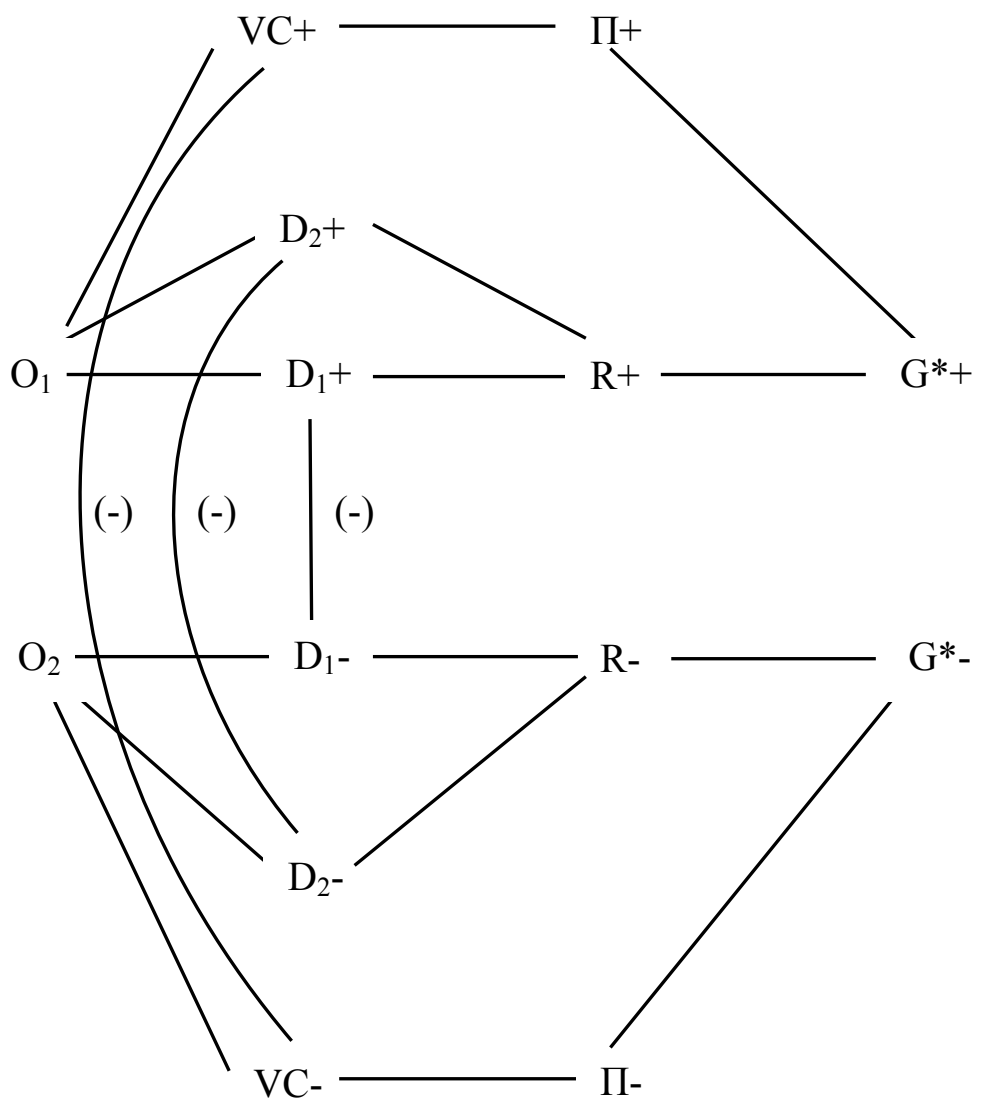

Notes: $\mathrm{P}=$ Evaluator (experimental subject), $\mathrm{O}_{1}=$ Offender, $\mathrm{O}_{2}=$ Victim; $\mathrm{D}_{1}(+), \mathrm{D}_{1}(-)=$ positively and negatively valued states of diffuse status characteristic (race); $\mathrm{D}_{2}(+), \mathrm{D}_{2}(-)=$ positively and negatively valued states of diffuse status characteristic (education); $\mathrm{VC}(+), \mathrm{VC}(-)=$ positively and negatively valued status of valued personal characteristic (appropriate emotional display); $\Pi(+), \Pi(-)=$ positivity element (i.e., other information) derived from $\mathrm{VC} ; \mathrm{R}(+), \mathrm{R}(-)=$ generalized reward expectation states; $\mathrm{G}^{*}(+), \mathrm{G}^{*}(-)=$ goal object expectations.

\section{Numerical Computations}

We follow the procedures used in Berger et al. (1992) using path weights based on the empirical values by Berger et al. (1997) but adjusted according to criteria offered by Balkwell (1991).

Offender $\left(\mathrm{O}_{1}\right)$

$O_{1}$ 's Positive Paths 


$$
\begin{aligned}
e_{O_{1}}^{+} & =[1-(1-f(3))(1-f(3))(1-f(3))(1-f(4))(1-f(4))(1-f(4))] \\
& =[1-(1-0.41)(1-0.41)(1-0.41)(1-0.15)(1-0.15)(1-0.15)] \\
& =0.87
\end{aligned}
$$

$O_{1}$ 's Negative Paths

$e_{O_{1}}^{-}=[1-(1-f(0)]$

$=[1-(1-0)]$

$=0$

$O_{1}$ 's Aggregated Expectation

$e_{O_{1}}=e_{O_{1}}^{+}-e_{O_{1}}^{-}$

$=0.87-0$

$=0.87$

$\underline{\operatorname{Victim}\left(\mathrm{O}_{2}\right)}$

$\mathrm{O}_{2}$ 's Aggregated Expectation (by symmetry)

$e_{\mathrm{O}_{2}}=-0.87$

\section{Offender Expectation Advantage}

$$
\begin{aligned}
e & =e_{O_{1}}-e_{O_{2}} \\
& =0.87-(-0.87) \\
& =1.74
\end{aligned}
$$


Appendix C. Composite Variables and Manipulation Checks

Table C.1. Composite Variable Properties

\begin{tabular}{llcc}
\hline Composite Measure & Cronbach's $\boldsymbol{\alpha}$ & Mean & $\begin{array}{c}\text { Standard } \\
\text { Deviation }\end{array}$ \\
\hline Dependent Variables & & & \\
Offender Dangerousness & .73 & 3.94 & 1.88 \\
Offense Seriousness & .79 & 6.25 & 1.39 \\
Recommended Sentence & .96 & 1.89 & 0.47 \\
\hline
\end{tabular}

Notes: With the exception of recommended sentence, all composite measures are on a 9-point Likert scale. Recommended sentence is a logged variable. 
Table C.2. $t$-Tests of Mean Emotion Ratings by Manipulation

\begin{tabular}{|c|c|c|c|c|c|c|}
\hline & \multicolumn{6}{|c|}{ Manipulated Emotion } \\
\hline & $\begin{array}{l}\text { Remorseful } \\
\text { Offender }\end{array}$ & $\begin{array}{l}\text { Unemotional } \\
\text { Offender }\end{array}$ & $t$-statistic & $\begin{array}{l}\text { Depressed } \\
\text { Victim }\end{array}$ & $\begin{array}{l}\text { Unemotional } \\
\text { Victim }\end{array}$ & $t$-statistic \\
\hline \multicolumn{7}{|l|}{ Survey Item } \\
\hline $\begin{array}{l}\text { In your opinion, how sad was the offender } \\
\text { (victim)? }\end{array}$ & $\begin{array}{c}7.56 \\
(1.45)\end{array}$ & $\begin{array}{c}4.62 \\
(2.06)\end{array}$ & $19.19 * * *$ & $\begin{array}{c}7.83 \\
(1.38)\end{array}$ & $\begin{array}{c}5.86 \\
(2.03)\end{array}$ & $13.19 * * *$ \\
\hline $\begin{array}{l}\text { In your opinion, how upset was the offender } \\
\text { (victim)? }\end{array}$ & $\begin{array}{c}7.71 \\
(1.37)\end{array}$ & $\begin{array}{c}5.00 \\
(2.08)\end{array}$ & $17.81 * * *$ & $\begin{array}{c}8.24 \\
(1.11)\end{array}$ & $\begin{array}{c}6.27 \\
(2.03)\end{array}$ & $14.02 * * *$ \\
\hline $\begin{array}{l}\text { In your opinion, how calm was the offender } \\
\text { (victim) } ?^{\mathrm{a}}\end{array}$ & $\begin{array}{c}7.76 \\
(1.39)\end{array}$ & $\begin{array}{c}5.01 \\
(2.21)\end{array}$ & $17.35 * * *$ & $\begin{array}{c}8.05 \\
(1.35)\end{array}$ & $\begin{array}{c}6.27 \\
(2.13)\end{array}$ & $11.63 * * *$ \\
\hline $\begin{array}{l}\text { In your opinion, how unconcerned was the } \\
\text { offender (victim)? }^{\text {a }}\end{array}$ & $\begin{array}{c}6.36 \\
(1.97)\end{array}$ & $\begin{array}{c}3.41 \\
(1.97)\end{array}$ & $17.45^{* * *}$ & $\begin{array}{c}5.61 \\
(2.18)\end{array}$ & $\begin{array}{c}3.02 \\
(1.75)\end{array}$ & $15.23 * * *$ \\
\hline $\begin{array}{l}\text { In your opinion, how remorseful was the } \\
\text { offender? }\end{array}$ & $\begin{array}{l}6.96 \\
(2.55)\end{array}$ & $\begin{array}{l}5.35 \\
(2.23)\end{array}$ & $7.80 * * *$ & ----- & ----- & ----- \\
\hline $\begin{array}{l}\text { In your opinion, how depressed was the } \\
\text { victim? }\end{array}$ & ----- & ----- & ----- & $\begin{array}{l}6.96 \\
(2.69)\end{array}$ & $\begin{array}{c}5.68 \\
(2.42)\end{array}$ & $5.80 *$ \\
\hline$n$ & 272 & 269 & & 269 & 272 & \\
\hline
\end{tabular}


Table C.3. $t$-Tests of Mean Status Ratings by Manipulation

\begin{tabular}{|c|c|c|c|c|c|c|}
\hline & \multicolumn{6}{|c|}{ Manipulated Status } \\
\hline & $\begin{array}{l}\text { High Status } \\
\text { Offender }\end{array}$ & $\begin{array}{l}\text { Low Status } \\
\text { Offender }\end{array}$ & $t$-statistic & $\begin{array}{l}\text { High Status } \\
\text { Victim }\end{array}$ & $\begin{array}{l}\text { Low Status } \\
\text { Victim }\end{array}$ & $t$-statistic \\
\hline \multicolumn{7}{|l|}{ Survey Item } \\
\hline $\begin{array}{l}\text { In your opinion, how much status does the } \\
\text { offender (victim) generally possess? }\end{array}$ & $\begin{array}{c}6.78 \\
(1.47)\end{array}$ & $\begin{array}{c}4.09 \\
(1.56)\end{array}$ & $20.57^{*}$ & $\begin{array}{c}6.24 \\
(1.45)\end{array}$ & $\begin{array}{c}4.14 \\
(1.47)\end{array}$ & $16.79^{*}$ \\
\hline $\begin{array}{l}\text { In your opinion, how much prestige does the } \\
\text { offender (victim) generally possess? }\end{array}$ & $\begin{array}{c}6.61 \\
(1.69)\end{array}$ & $\begin{array}{c}3.88 \\
(1.71)\end{array}$ & $18.69^{*}$ & $\begin{array}{c}6.15 \\
(1.49)\end{array}$ & $\begin{array}{c}4.22 \\
(1.71)\end{array}$ & $14.05^{*}$ \\
\hline $\begin{array}{l}\text { In your opinion, how much honor does the } \\
\text { offender (victim) generally possess? }\end{array}$ & $\begin{array}{c}4.84 \\
(2.28)\end{array}$ & $\begin{array}{c}3.92 \\
(1.88)\end{array}$ & $5.06^{*}$ & $\begin{array}{c}6.57 \\
(1.37)\end{array}$ & $\begin{array}{c}5.82 \\
(1.72)\end{array}$ & $5.66^{*}$ \\
\hline$n$ & 273 & 268 & & 267 & 274 & \\
\hline
\end{tabular}

Notes: Standard deviations in parentheses.

$* p<.05 ; * * p<.01 ; * * * p<.001$ (two-tailed tests) 